\title{
RELAÇÃO DAS VARIÁVEIS CONCERNENTES AO DESEMPENHO ACADÊMICO: UM ESTUDO COM ALUNOS DE GRADUAÇÃO EM CIÊNCIAS CONTÁBEIS
}

\section{RELATIONSHIP OF VARIABLES CONCERNING ACADEMIC PERFORMANCE: A STUDY UNDERGRATUATE STUDENTS IN ACCOUNTING}

\section{RELACIÓN DE LAS VARIABLES CONCERNENTES AL DESEMPEÑO ACADÉMICO: UN ESTUDIO CON ALUMNOS DE GRADUACIÓN EN CIENCIAS CONTABLES}

Recebido em: 24/07/2017

Avaliado em: 07/12/2018

Reformulado em:30/03/2019

Aceito para publicação em: 31/05/2018

Publicado em: 14/06/2019

Editor Responsável: Marcia Zanievicz Silva

\author{
Zilton Bartolomeu Martins ${ }^{1}$
}

Sidnei Vieira Marinho ${ }^{2}$

\section{RESUMO}

Este estudo teve como objetivo analisar a relação entre as variáveis concernentes às dimensões corpo docente, corpo discente e IES com a variável desempenho acadêmico. Em relação ao método, este trabalho é classificado como quantitativo em função da utilização de técnicas estatísticas e descritivo decorrente do objetivo geral. Quanto aos procedimentos, classifica-se como pesquisa de levantamento por conta da aplicação de questionário e também como documental, devido ao uso de documentos como fonte de dados. Como instrumento de coleta de dados, utilizou-se um questionário com vinte questões fechadas, baseado nos autores Andrade e Corrar (2008), Souza (2008) e Ferreira (2015). A população deste estudo foi de 617 alunos, resultando em uma amostra de 361 respondentes. Para análise, utilizou-se técnicas estatísticas univariadas, como o Alfa de Cronbach, a prova KolmogorovSmirnov para o teste de normalidade e os coeficientes de correlação ponto-bisserial e de Spearman para a análise dos dados. Como principais resultados identificou-se que as variáveis estratégia ou método de ensino (dimensão corpo docente), status socioeconômico, absenteísmo, desempenho escolar anterior, horas de estudo e motivação (dimensão corpo discente) e ambiente de estudo e forma de ingresso (dimensão IES) possuem relação com a variável desempenho acadêmico.

Palavras-Chave: Desempenho acadêmico. Alunos. Ciências Contábeis.

\section{ABSTRACT}

This study had the objective analyze the relationship between the variables concerning the faculty, student body and HEI dimensions with the variable academic performance. In relation to method, this work is classified as quantitative according to the use of statistical and descriptive techniques deriving from the general objective. As for the procedures, it is classified as a survey, as it uses a questionnaire, and also documentary, as it uses documents as the data source. The questionnaire used as the collection instrument was twenty closed questions, based on the authors Andrade and Corrar (2008),

\footnotetext{
${ }^{1}$ Mestre em Administração pela Universidade do Vale do Itajaí; E-mail: ziltonmartins@ univali.br

${ }^{2}$ Doutor em Engenharia de Produção pela Universidade Federal de Santa Catarina; Professor da Universidade do Vale do Itajaí; E-mail: sidnei@ univali.br
} 
Souza (2008) and Ferreira (2015). The study population consisted of 617 students, resulting in a sample of 361 respondents. For analysis, then univariate statistical techniques were used, such as Cronbach's Alpha for the reliability test, the Kolmogorov-Smirnov test of normality, and the pointbisserial and Spearman's rank correlation coefficients for the analysis of the data. As the main results, it was identified that the variables teaching strategy or method (faculty dimension), socioeconomic status, absenteeism, previous school performance, hours of study and motivation (student body dimension) and study environment and form of entry to the institution (HEI dimension) are related to the variable academic performance.

Keywords: Academic Performance. Students. Accounting.

\section{RESUMEN}

Este estudio tuvo como objetivo analizar la relación entre las variables concernientes a las dimensiones cuerpo docente, cuerpo discente y IES con la variable desempeño académico. En relación con el método, este trabajo se clasifica como cuantitativo en función de la utilización de técnicas estadísticas y descriptivas derivadas del objetivo general. Cuanto a los procedimientos, se clasifica como encuesta de levantamiento por cuenta de la aplicación de cuestionario y también como documental, debido al uso de documentos como fuente de datos. Como instrumento de recolección de datos, se utilizó un cuestionario con veinte cuestiones cerradas, basado en los autores Andrade y Corrar (2008), Souza (2008) y Ferreira (2015). La población de este estudio fue de 617 alumnos, resultando en una muestra de 361 respondedores. Para el análisis, se utilizaron técnicas estadísticas univariadas, como el Alfa de Cronbach, la prueba Kolmogorov-Smirnov para la prueba de normalidad y los coeficientes de correlación punto-bisserial y de Spearman para el análisis de los datos. Como principales resultados, se identificó que las variables estrategia o método de enseñanza (dimensión cuerpo docente), estatus socioeconómico, absentismo, desempeño escolar anterior, horas de estudio y motivación (dimensión del alumnado) y ambiente de estudio y forma de ingreso la dimensión IES) tienen relación con la variable desempeño académico.

Palabras-Clave: Desempeño Académico. Alumnos. Ciencias Contables.

\section{INTRODUÇÃO}

A expansão no número de Instituições de Ensino Superior (IES) e número de vagas ofertadas a partir do final do século XX, pode ser considerada uma importante e positiva ação em prol do desenvolvimento da economia e do capital humano, visto que com o ingresso ao ensino superior para uma maior parte da população, mais pessoas se beneficiam com os impactos decorrentes de um diploma de graduação, inclusive, o possível aumento da renda pessoal deste diplomado (Miranda, 2011; Das, 2014; Maniates, 2017).

Neste contexto, se faz necessário identificar as características das IES que oferecem serviços educacionais vinculados ao ensino, à pesquisa e à extensão, não esquecendo-se da qualidade do serviço oferecido. Sendo assim, é possível observar que essa qualidade, assim como o crescimento quantitativo da educação superior é uma preocupação mundial (Ru-Jer, 2012; Das, 2014; Mancebo, Vale, \& Martins, 2015; Smolentseva, 2016). Em complemento, a partir da atenção dada à qualidade do ensino, o conhecimento das variáveis que possuem relação com o desempenho acadêmico passou a ser indispensável na busca desta qualidade (Araújo et al., 2013; Schmidt, Zlatkin-Troitschankaia, \& Fox, 2016).

Neste contexto, o papel dos docentes universitários é ajudar os discentes a buscarem um alto desempenho acadêmico, desenvolvendo uma conexão apropriada entre capital intelectual e esforço (Liu, Robinson, \& Xu, 2018). Além disto, é importante que o professor adote diferentes estratégias e métodos de ensino como forma de melhorar o processo de ensino-aprendizagem e, possivelmente, também o desempenho acadêmico destes alunos (Alanzi, \& Alfraih, 2017; Meurer et al., 2018). 
Já em relação aos discentes, Moleta, Ribeiro e Clemente (2017) enfatizam que somente a presença dos acadêmicos no curso de graduação não é mais suficiente para definir uma carreira profissional promissora, uma vez que se torna necessário que o estudante se dedique e consiga absorver o máximo de conhecimento possível para conquistar seu espaço no mercado. Entretanto, o conhecimento acumulado adquirido durante o curso, assim como a preocupação com um alto desempenho acadêmico, pode exercer um importante papel para o ingresso deste discente no mercado de trabalho (Karakoc, 2016; Alanzi, \& Alfraih, 2017; Abina, \& Uthman, 2018).

Assim, Munhoz (2004) enfatiza que desempenho acadêmico é considerado no sentido da atuação observada de um único ou de um grupo de indivíduos na execução de tarefas acadêmicas que são avaliadas em termos de eficiência e rendimento. A identificação das variáveis concernentes ao desempenho acadêmico é uma preocupação constante tanto dos próprios discentes, como também dos docentes e equipes pedagógicas das IES (Nogueira et al., 2013; Schmidt, Zlatkin-Troitschankaia, \& Fox, 2016).

Ressalta-se que Corbucci (2007), Guney (2009), Glewwe et al. (2011) e Miranda et al. (2015) classificaram estas variáveis em três dimensões. Desta forma, é importante evidenciar que embora o conjunto de variáveis analisados sofra alterações entre os estudos, os autores citados as segregaram nestas três dimensões: corpo docente, corpo discente e IES. Sendo assim, cabe enfatizar que ainda não há uma adequada compreensão sobre tais variáveis, uma vez que diversos fatores podem interferir no desempenho acadêmico (Miranda et al., 2015).

Diante do contexto apresentado, torna-se oportuno abordar o assunto decorrente das mudanças no ensino causadas pelo crescimento de IES e vagas ofertadas. Além disto, conhecer as potencialidades e fragilidades das variáveis no processo de formação individual do aluno, pode facilitar a utilização de técnicas para a consolidação do ensino-aprendizagem (Ferreira, 2015; Zhang, 2015).

Neste sentido, pode-se atribuir a este estudo a seguinte pergunta de pesquisa: qual a relação entre as variáveis concernentes às dimensões corpo docente, corpo discente e IES com a variável desempenho acadêmico? Para que esta pergunta possa ser respondida, apresenta-se como objetivo analisar a relação entre as variáveis concernentes às dimensões corpo docente, corpo discente e IES com a variável desempenho acadêmico. A justificativa teórica deste artigo se baseia na relação das variáveis classificadas nas três dimensões (corpo docente, discente e IES) de forma conjunta com o desempenho acadêmico, conforme classificaram os autores Corbucci (2007), Guney (2009), Glewwe et al. (2011), Miranda et al. (2015) e Ferreira (2015).

Em relação à contribuição das pesquisas supracitadas, Corbucci (2007) discutiu a relação que se estabelece entre educação superior e desenvolvimento, no contexto societário brasileiro, Guney (2009) explorou transversalmente os determinantes potenciais de desempenho acadêmico em disciplinas de contabilidade para alunos de outros cursos de graduação, Glewwe et al. (2011) examinaram estudos publicados entre 1990 e 2010, para investigar quais características específicas da escola e do professor parecem ter impacto positivo na aprendizagem, Miranda et al. (2015) identificaram variáveis apresentadas na literatura que afetam o desempenho acadêmico no ensino superior na área de negócios e Ferreira (2015) identificou as variáveis significativas na explicação do resultado ENADE 2012 em Ciências Contábeis. Neste contexto, este artigo se difere dos estudos citados anteriormente por buscar uma possível relação entre as variáveis classificadas nas dimensões corpo docente, corpo discente e IES com a variável desempenho acadêmico e, desta forma, pretende avançar nesta discussão.

Como justificativa empírica, está a contribuição para a formação de profissionais contábeis capacitados a desempenhar seu papel na sociedade, além de auxiliar as equipes de gestão das IES a propor melhorias nos processos de avaliações do curso, sejam eles internos ou externos.

Este estudo contém, além desta introdução, um referencial teórico sobre desempenho acadêmico, os procedimentos metodológicos utilizados para a execução desta pesquisa, a análise dos dados obtidos e, por fim, as considerações finais deste artigo. 


\section{FUNDAMENTAÇÃO TEÓRICA}

Neste tópico são abordados assuntos relativos a indicadores para avaliação de desempenho acadêmico e dimensões e variáveis referentes ao desempenho acadêmico selecionadas a partir da revisão de literatura. Vale ressaltar que o primeiro item desta fundamentação teórica aborda como a literatura tem mensurado a avaliação de desempenho, enquanto o segundo evidencia a seleção das dimensões e variáveis referentes ao tema estudado.

\subsection{Indicadores para avaliação de desempenho acadêmico}

Santos (2012) afirma que desempenho acadêmico é o resultado do processo de produção educacional, cujo resultado é apresentado individualmente e suas alterações estão relacionadas a fatores inerentes ao aluno, ao professor ou à instituição de ensino. Miranda et al. (2015) complementam que desempenho acadêmico decorre de uma variedade de fatores, como a formação do corpo docente, a estrutura da IES, como bibliotecas e salas de aula e atributos dos próprios estudantes, como a forma que utilizam seu tempo e outras variáveis demográficas.

Em complemento, Wang (2017) sustenta que desempenho acadêmico é a maneira como o discente responde a objetivos previamente definidos, sejam eles de curto ou longo prazo, em busca de sua realização acadêmica. Entretanto, Salas-Velasco (2018) enfatiza que não existe nenhum acordo sobre uma possível definição do que é desempenho acadêmico, embora afirme que seja o resultado da maneira como os alunos despendem tempo e energia para aprimorar seus conhecimentos.

Por meio das avaliações, de um modo geral, é que ocorre a mensuração do desempenho acadêmico, mas para isto, torna-se necessário estabelecer uma base para análise. Estas bases podem ser mais simples ou complexas, podendo ser nota de uma avaliação, nota de uma disciplina, nota média do período ou média geral acumulada (Miranda et al., 2015). No Quadro 1 apresenta-se os autores, as variáveis estudadas e a forma de avaliação do desempenho acadêmico de estudos identificados na literatura.

É possível observar as variáveis mais incidentes decorrentes dos estudos que utilizaram medidas internas de mensuração do desempenho acadêmico, ou seja, as formas utilizadas pelas IES para medir o desempenho dos discentes (Miranda et al., 2015; Borges et al., 2018), são gênero, idade e horas de estudo e que o coeficiente de rendimento é a forma mais usual de avaliação do desempenho acadêmico. Neste contexto, York, Gibson e Rankin (2015) incentivam a ampliação de pesquisas que utilizem notas para mensurar o desempenho acadêmico dos discentes, devido à facilidade de acesso destes dados perante às IES. Os autores ainda salientam que o Coeficiente de Rendimento Acadêmico (CRA) é a maneira mais frequente de mensuração do desempenho acadêmico, conforme observa-se na literatura.

Ressalta-se que o desempenho acadêmico também pode ser investigado por meio de sistemas de avaliação externos, como o Exame Nacional de Cursos (ENC), o Exame Nacional de Desempenho de Estudantes (ENADE) e Exame de Suficiência do Conselho Federal de Contabilidade (CFC). Desta forma, no ano de 1995 foi criado o ENC, que foi aplicado aos formandos de Ciências Contábeis (dentre outros cursos) no período de 1996 a 2003, posteriormente substituído pelo ENADE, em 2004 (INEP, 2017). O ENC que também ficou conhecido como "Provão", foi um exame realizado com os concluintes dos cursos de graduação, entretanto, o ENADE integra o Sistema Nacional de Avaliação da Educação Superior (SINAES) e veio substituir o ENC. O exame objetiva mensurar o desempenho dos estudantes em relação aos conteúdos programáticos previstos nas diretrizes curriculares do respectivo curso de graduação, assim como as habilidades e competências em sua formação (INEP, 2017).

Desta forma, no Quadro 2 apresenta-se um resumo dos autores, variáveis e principais resultados dos estudos identificados na literatura que se correlacionam com o desempenho obtido pelos alunos nas avaliações aplicadas por meio do ENC ou ENADE. 
Quadro 1 - Forma de avaliação do desempenho acadêmico

\begin{tabular}{|c|c|c|}
\hline Autores & Variáveis & $\begin{array}{l}\text { Forma de avaliação do } \\
\text { desempenho acadêmico }\end{array}$ \\
\hline Guney (2009) & $\begin{array}{c}\text { Qualificação Pedagógica, Gênero, Idade, Absenteísmo, } \\
\text { Desempenho Escolar Anterior, Atividade Remunerada, } \\
\text { Horas de Estudo e Tamanho da Turma }\end{array}$ & $\begin{array}{l}\text { Notas de avaliações dos } \\
\text { alunos em módulos de } \\
\text { Contabilidade }\end{array}$ \\
\hline $\begin{array}{l}\text { Cornachione Júnior et al. } \\
\qquad(2010)\end{array}$ & $\begin{array}{c}\text { Gênero, Idade, Participação em Projetos de Iniciação } \\
\text { Científica, Pesquisa ou Extensão e Horário da Disciplina } \\
\text { (Turno) }\end{array}$ & $\begin{array}{l}\text { Autoavaliação dos } \\
\text { alunos }\end{array}$ \\
\hline Paiva e Lourenço (2011) & Gênero, Desempenho Escolar Anterior e Horas de Estudo & $\begin{array}{l}\text { Notas obtidas em Língua } \\
\text { Portuguesa e Matemática }\end{array}$ \\
\hline $\begin{array}{l}\text { Ferreira e Crisóstomo } \\
(2012)\end{array}$ & Status Socioeconômico & \multirow{2}{*}{$\begin{array}{l}\text { Nota final das } \\
\text { disciplinas }\end{array}$} \\
\hline Araújo et al. (2013) & Gênero, Idade e Absenteísmo & \\
\hline Burrus e Graham (2009) & Horas de Sono & \multirow{4}{*}{$\begin{array}{l}\text { Coeficiente de } \\
\text { Rendimento dos alunos } \\
\text { (CRA) }\end{array}$} \\
\hline Soares e Barbedo (2013) & Gênero e Idade & \\
\hline $\begin{array}{l}\text { Lepp, Barkley e Karpinski } \\
\text { (2014) }\end{array}$ & Gênero, Idade e Nível de Ansiedade & \\
\hline Mamede et al. (2015) & Gênero, Idade e Estado Civil & \\
\hline $\begin{array}{l}\text { Moura, Miranda e Pereira } \\
\text { (2015) }\end{array}$ & $\begin{array}{c}\text { Estratégia ou Método de Ensino, Escolaridade dos Pais, } \\
\text { Absenteísmo, Desempenho Escolar Anterior, Horas de } \\
\text { Estudo, Comportamentais (Motivação e Nível de } \\
\text { Ansiedade), Participação em Projetos de Iniciação } \\
\text { Científica, Pesquisa ou Extensão, Frequência de Utilização } \\
\text { da Biblioteca e Tamanho da Turma }\end{array}$ & \multirow{7}{*}{$\begin{array}{l}\text { Coeficiente de } \\
\text { Rendimento dos alunos } \\
\text { (CRA) }\end{array}$} \\
\hline Andrietti e Velasco (2015) & $\begin{array}{l}\text { Gênero, Idade, Horas de Estudo e Horário da Disciplina } \\
\text { (Turno) }\end{array}$ & \\
\hline Rangel e Miranda (2016) & $\begin{array}{c}\text { Gênero, Atividade Remunerada, Horas de Estudo e } \\
\text { Motivação }\end{array}$ & \\
\hline $\begin{array}{c}\text { Mehmood, Sadaf e Kousar } \\
\text { (2017) }\end{array}$ & Gênero, Status Socioeconômico e Escolaridade dos Pais & \\
\hline Zaidi et al. (2017) & $\begin{array}{l}\text { Estratégia ou Método de Ensino, Idade, Status } \\
\text { Socioeconômico, Horas de Estudo e Motivação }\end{array}$ & \\
\hline $\begin{array}{l}\text { Haile, Alemu e Hablewold } \\
\text { (2017) }\end{array}$ & Gênero e Horas de Sono & \\
\hline Smirnov e Thurner (2017) & Gênero e Idade & \\
\hline
\end{tabular}

Fonte: Elaborado pelos autores (2017).

\section{Quadro 2 - Desempenho acadêmico investigado por meio do ENC ou ENADE}

\begin{tabular}{|c|c|c|}
\hline Quadro 2 - Desempenho acadêmico investigado por meio do ENC ou ENADE & Principais Resultados \\
\hline $\begin{array}{c}\text { Nascimento } \\
(2005)\end{array}$ & $\begin{array}{c}\text { Variáveis } \\
\text { Qualificação Pedagógica e } \\
\text { Experiência Profissional }\end{array}$ & $\begin{array}{c}\text { A formação do corpo docente, seja acadêmica ou profissional, } \\
\text { por si só não eliminou o problema de baixo desempenho } \\
\text { acadêmico. }\end{array}$ \\
\hline Diaz (2007) & $\begin{array}{c}\text { Gênero, Idade e Status } \\
\text { Socioeconômico }\end{array}$ & $\begin{array}{c}\text { A condição econômica dos alunos é importante como } \\
\text { determinante do rendimento dos mesmos. Os resultados também } \\
\text { indicaram que indivíduos mais velhos tendem a apresentar um } \\
\text { pior desempenho do que os mais jovens e que as mulheres, } \\
\text { controlados os demais fatores, tenderam a apresentar piores } \\
\text { resultados do que os homens. Por fim, verificaram que maiores } \\
\text { percentuais de mestres e doutores no quadro docente, produzem } \\
\text { impactos efetivos sobre o rendimento dos alunos. }\end{array}$ \\
\hline
\end{tabular}

Continua... 


\begin{tabular}{|c|c|c|}
\hline Autores & $\begin{array}{l}\text { Variáveis } \\
\end{array}$ & Principais Resultados \\
\hline $\begin{array}{c}\text { Andrade e } \\
\text { Corrar }(2008)\end{array}$ & $\begin{array}{l}\text { Estratégia ou Método de Ensino, } \\
\text { Status Socioeconômico, } \\
\text { Escolaridade dos Pais, Estado } \\
\text { Civil, Atividade Remunerada, } \\
\text { Horas de Estudo, Participação } \\
\text { em Projetos de Iniciação } \\
\text { Científica, Pesquisa ou } \\
\text { Extensão, Frequência de } \\
\text { Utilização da Biblioteca e } \\
\text { Tamanho da Turma }\end{array}$ & $\begin{array}{l}\text { Concluem que todas as variáveis escolhidas para análise estão } \\
\text { relacionadas com o desempenho dos estudantes. }\end{array}$ \\
\hline $\begin{array}{l}\text { Cruz, Corrar } \\
\text { e Slomski } \\
\quad(2008)\end{array}$ & $\begin{array}{l}\text { Estratégia ou Método de Ensino, } \\
\text { Ambiente de Estudo e } \\
\text { Frequência de Utilização da } \\
\text { Biblioteca }\end{array}$ & $\begin{array}{l}\text { Diferentes técnicas de ensino também provocaram diferentes } \\
\text { desempenhos e quanto aos recursos didáticos, alunos que } \\
\text { utilizaram livros apresentaram melhor desempenho que os que } \\
\text { usaram apostilas. Por fim, o ambiente especializado para estudos } \\
\text { não impactou no desempenho dos alunos. }\end{array}$ \\
\hline Souza (2008) & $\begin{array}{l}\text { Status Socioeconômico, } \\
\text { Escolaridade dos Pais, } \\
\text { Desempenho Escolar Anterior e } \\
\text { Horas de Estudo }\end{array}$ & $\begin{array}{l}\text { O nível de formação do aluno anterior ao seu ingresso em uma } \\
\text { IES é a variável de maior influência no desempenho dos cursos. } \\
\text { Em seguida, em ordem decrescente, surgem a escolaridade do } \\
\text { pai, o esforço pessoal no curso e a renda familiar como as } \\
\text { variáveis mais influentes. Por fim, a escolaridade da mãe } \\
\text { mostrou-se negativamente correlacionada com o desempenho do } \\
\text { curso, porém, se tomada em conjunto com a escolaridade do pai, } \\
\text { verificou-se que a escolaridade dos pais influencia positivamente } \\
\text { a predição do desempenho. }\end{array}$ \\
\hline $\begin{array}{l}\text { Miranda } \\
(2011)\end{array}$ & $\begin{array}{l}\text { Qualificação Pedagógica e } \\
\text { Experiência Profissional }\end{array}$ & $\begin{array}{c}\text { A qualificação pedagógica e experiência profissional não } \\
\text { apresentaram correlações significativas. }\end{array}$ \\
\hline Santos (2012) & $\begin{array}{l}\text { Gênero, Idade, Etnia, Status } \\
\text { Socioeconômico, Escolaridade } \\
\text { dos Pais, Estado Civil, Número } \\
\text { de Filhos, Horas de Estudo e } \\
\text { Participação em Projetos de } \\
\text { Iniciação Científica, Pesquisa ou } \\
\text { Extensão }\end{array}$ & $\begin{array}{l}\text { Associação significativa entre o desempenho acadêmico dos } \\
\text { estudantes concluintes de Ciências Contábeis e variáveis como } \\
\text { gênero, horas de dedicação aos estudos, faixa de renda familiar e } \\
\text { professores que utilizaram como prática de ensino predominante } \\
\text { a aula expositiva. Na categoria efeitos dos pares, foi encontrada } \\
\text { relação negativa e significativa do desempenho acadêmico do } \\
\text { estudante por ser solteiro. }\end{array}$ \\
\hline $\begin{array}{l}\text { Zonatto et al. } \\
\qquad(2013)\end{array}$ & Titulação & $\begin{array}{l}\text { As universidades com maior proporção média de mestres } \\
\text { atingiram melhores conceitos. Por fim, observou-se uma } \\
\text { correlação positiva entre o desempenho acadêmico com a } \\
\text { proporção total de mestres e doutores. }\end{array}$ \\
\hline $\begin{array}{l}\text { Miranda, } \\
\text { Casanova e } \\
\text { Cornachione } \\
\text { Júnior (2013) }\end{array}$ & $\begin{array}{l}\text { Titulação, Qualificação } \\
\text { Pedagógica e Experiência } \\
\text { Profissional }\end{array}$ & $\begin{array}{l}\text { As variáveis titulação e qualificação pedagógica possuem uma } \\
\text { correlação positiva com o desempenho acadêmico, enquanto a } \\
\text { variável experiência profissional não se mostrou significativa. }\end{array}$ \\
\hline $\begin{array}{l}\text { Lemos e } \\
\text { Miranda } \\
(2015)\end{array}$ & $\begin{array}{l}\text { Titulação e Escolaridade dos } \\
\text { Pais }\end{array}$ & $\begin{array}{l}\text { As universidades com maior proporção de professores com } \\
\text { titulação de mestres e doutores obtiveram melhor desempenho. } \\
\text { Entretanto, a variável escolaridade dos pais não apresentou } \\
\text { significância. }\end{array}$ \\
\hline $\begin{array}{l}\text { Ferreira } \\
(2015)\end{array}$ & $\begin{array}{l}\text { Titulação, Gênero, Idade, Etnia, } \\
\text { Status Socioeconômico, } \\
\text { Escolaridade dos Pais, Estado } \\
\text { Civil, Número de Filhos, } \\
\text { Desempenho Escolar Anterior, } \\
\text { Atividade Remunerada, Horas } \\
\text { de Estudo, Ambiente de Estudo, } \\
\text { Frequência de Utilização da } \\
\text { Biblioteca, Tamanho da Turma, } \\
\text { Horário da Disciplina (Turno) e } \\
\text { Forma de Ingresso }\end{array}$ & $\begin{array}{l}\text { A maioria dos alunos é do gênero feminino e a maior parte dos } \\
\text { discentes encontra-se entre } 19 \text { e } 30 \text { anos, com renda familiar de } \\
\text { até quatro salários mínimos e meio e a maior parte se declara } \\
\text { branco ou amarelo. A maioria ingressou no ensino superior por } \\
\text { meio de processo seletivo normal, cursa o turno noturno, sendo } \\
\text { oriundo de famílias cujos pais possuem até o ensino médio como } \\
\text { escolaridade. Também foi destacado o fato de que as mulheres, } \\
\text { embora serem a maioria, tendem a apresentar desempenho } \\
\text { menor que o dos homens. Por fim, a escolaridade do pai não } \\
\text { apresentou significância, enquanto a escolaridade da mãe } \\
\text { apresentou relação negativa com o desempenho. }\end{array}$ \\
\hline
\end{tabular}




\begin{tabular}{|c|c|c|}
\hline Autores & Variáveis & Principais Resultados \\
\hline $\begin{array}{l}\text { Rodrigues et } \\
\text { al. (2016) }\end{array}$ & $\begin{array}{c}\text { Gênero, Idade, Etnia, Status } \\
\text { Socioeconômico, Escolaridade } \\
\text { dos Pais, Estado Civil, Atividade } \\
\text { Remunerada, Horas de Estudo, } \\
\text { Participação em atividades de } \\
\text { Iniciação Científica, Pesquisa ou } \\
\text { Extensão, Frequência de } \\
\text { utilização da Biblioteca e Forma } \\
\text { de Ingresso }\end{array}$ & $\begin{array}{l}\text { As variáveis que mais fortemente explicam o desempenho } \\
\text { acadêmico dos acadêmicos são o gênero, estado civil, etnia e } \\
\text { horas de estudo. }\end{array}$ \\
\hline
\end{tabular}

Fonte: Elaborado pelos autores (2017).

Percebe-se que os estudos supracitados evidenciaram um conjunto amplo de variáveis capazes de influenciar o desempenho investigado pelo ENC e atualmente pelo ENADE. As variáveis mais incidentes nestes estudos foram gênero e idade (como ocorreu nos estudos selecionados no tópico avaliação do desempenho acadêmico), titulação, escolaridade dos pais e status socioeconômico.

Já em relação ao Exame de Suficiência, instituído pelo CFC no ano de 2011, é uma avaliação obrigatória para os bacharéis em Ciências Contábeis que desejam obter o registro profissional (Conselho Federal de Contabilidade, 2015). Atualmente, para aprovação, o candidato deve atingir um desempenho igual ou superior a 50\% de acertos. Observa-se que para que os bacharéis em Ciências Contábeis possam exercer a profissão de Contador é necessário que os mesmos sejam aprovados no exame de suficiência do CFC, com o intuito de assegurar a qualidade dos serviços prestados, por meio de um mínimo de conhecimentos necessários para que o profissional possa desempenhar suas atribuições (Souza, Cruz, \& Lyrio, 2017).

Cabe evidenciar que além de fornecer habilitação profissional para o futuro registro, o exame de suficiência pode servir como instrumento de apoio às IES no processo de avaliação e acompanhamento de seus cursos, pois por meio das provas, é possível verificar os conteúdos que são exigidos e compará-los com aqueles ministrados nas aulas (Madeira, Mendonça, \& Abreu, 2003).

Ressalta-se que diferente do ENC e do Exame ENADE, o CFC não disponibiliza seus dados para as IES ou terceiros, razão pela qual não foram selecionadas pesquisas que utilizassem este exame como forma de investigação do desempenho acadêmico. Tal afirmação é reforçada por Galvão (2016), que enfatiza que o exame seria útil para avaliar as IES, caso os resultados fossem divulgados pelo CFC.

\subsection{Dimensões e variáveis referentes ao desempenho acadêmico selecionadas a partir da revisão de literatura}

O desempenho acadêmico decorre de variáveis relacionadas às dimensões corpo docente, corpo discente e IES (Araújo et al., 2013). Neste sentido, a dimensão corpo docente representa características relacionadas à qualificação acadêmica ou profissional dos docentes. A dimensão corpo discente diz respeito às características internas ou externas do próprio estudante e a dimensão IES se refere às características da instituição de ensino (Miranda et al., 2015). Diante disto, as variáveis selecionadas a partir da revisão da literatura, segregadas nas dimensões corpo docente, corpo discente e IES, estão sumarizadas no Quadro 3.

Desta forma, o Quadro 3 contém quatro variáveis na dimensão corpo docente, 14 variáveis na dimensão corpo discente e cinco variáveis na dimensão IES, o que totaliza 23 variáveis descritas na literatura as quais podem ter relação com o desempenho acadêmico. Ressalta-se ainda, que as variáveis que se destacaram, pela recorrência de utilização foram gênero, idade, horas de estudo, status socioeconômico e escolaridade dos pais.

Neste contexto, evidencia-se que a revisão de literatura apontou que a dimensão corpo docente possui três de quatro variáveis significativas em relação ao desempenho acadêmico (titulação, 
RELAÇÃO DAS VARIÁVEIS CONCERNENTES AO DESEMPENHO ACADÊMICO: UM ESTUDO COM ALUNOS DE GRADUAÇÃO EM CIÊNCIAS CONTÁBEIS

Quadro 3 - Dimensões e variáveis selecionadas a partir da revisão de literatura

\begin{tabular}{|c|c|c|}
\hline Dimensões & Variáveis & Autores \\
\hline \multirow{4}{*}{$\begin{array}{l}\text { Corpo } \\
\text { Docente }\end{array}$} & Titulação & $\begin{array}{l}\text { Zonatto et al. (2013), Miranda, Casanova e Cornachione Júnior (2013), } \\
\text { Miranda et al. (2015), Lemos e Miranda (2015) e Ferreira (2015) }\end{array}$ \\
\hline & $\begin{array}{l}\text { Qualificação } \\
\text { Pedagógica }\end{array}$ & $\begin{array}{l}\text { Nascimento (2005), Guney (2009), Miranda (2011) e Miranda, Casanova e } \\
\text { Cornachione Júnior (2013) }\end{array}$ \\
\hline & $\begin{array}{l}\text { Experiência } \\
\text { Profissional }\end{array}$ & $\begin{array}{l}\text { Nascimento (2005), Miranda (2011), Miranda, Casanova e Cornachione } \\
\text { Júnior (2013) e Miranda et al. (2015) }\end{array}$ \\
\hline & $\begin{array}{l}\text { Estratégia ou Método } \\
\text { de Ensino }\end{array}$ & $\begin{array}{l}\text { Andrade e Corrar (2008), Cruz, Corrar e Slomski (2008), Miranda et al. } \\
\text { (2015) e Moura, Miranda e Pereira (2015) }\end{array}$ \\
\hline \multirow{14}{*}{$\begin{array}{l}\text { Corpo } \\
\text { Discente }\end{array}$} & Gênero & $\begin{array}{l}\text { Diaz (2007), Guney (2009), Cornachione Júnior et al. (2010), Paiva e } \\
\text { Lourenço (2011), Ballester (2012), Santos (2012), Araújo et al. (2013), } \\
\text { Soares e Barbedo (2013), Miranda et al. (2015), Mamede et al. (2015), } \\
\text { Ferreira (2015), Rangel e Miranda (2016), Rodrigues et al. (2016), Lin et al. } \\
\text { (2017) e Mehmood, Sadaf e Kousar (2017) }\end{array}$ \\
\hline & Idade & $\begin{array}{l}\text { Diaz (2007), Guney (2009), Cornachione Júnior et al. (2010), Ballester } \\
\text { (2012), Santos (2012), Araújo et al. (2013), Soares e Barbedo (2013), } \\
\text { Miranda et al. (2015), Mamede et al. (2015), Ferreira (2015), Rodrigues et } \\
\text { al. (2016) e Lin et al. (2017) }\end{array}$ \\
\hline & Etnia & $\begin{array}{l}\text { Keef e Roush (1997), Eikner e Montondon (2001), Santos (2012), Miranda } \\
\text { et al. (2015), Ferreira (2015), Rodrigues et al. (2016) e Lin et al. (2017) }\end{array}$ \\
\hline & Status Socioeconômico & $\begin{array}{l}\text { Diaz (2007), Andrade e Corrar (2008), Souza (2008), Ferreira e Crisóstomo } \\
\text { (2012), Santos (2012), Miranda et al. (2015), Ferreira (2015) e Rodrigues et } \\
\text { al. (2016) }\end{array}$ \\
\hline & Escolaridade dos Pais & $\begin{array}{l}\text { Andrade e Corrar (2008), Souza (2008), Santos (2012), Miranda et al. } \\
\text { (2015), Lemos e Miranda (2015), Moura, Miranda e Pereira (2015), Ferreira } \\
\text { (2015) e Rodrigues et al. (2016) }\end{array}$ \\
\hline & Estado Civil & $\begin{array}{l}\text { Andrade e Corrar (2008), Santos (2012), Masasi (2012), Miranda et al. } \\
\text { (2015), Mamede et al. (2015), Ferreira (2015) e Rodrigues et al. (2016) }\end{array}$ \\
\hline & Número de Filhos & Santos (2012), Masasi (2012), Miranda et al. (2015) e Ferreira (2015) \\
\hline & Absenteísmo & $\begin{array}{l}\text { Guney (2009), Araújo et al. (2013), Miranda et al. (2015) e Moura, Miranda } \\
\text { e Pereira (2015) }\end{array}$ \\
\hline & $\begin{array}{l}\text { Desempenho Escolar } \\
\text { Anterior }\end{array}$ & $\begin{array}{l}\text { Souza (2008), Guney (2009), Paiva e Lourenço (2011), Ballester (2012), } \\
\text { Miranda et al. (2015), Moura, Miranda e Pereira (2015) e Ferreira (2015) }\end{array}$ \\
\hline & Atividade Remunerada & $\begin{array}{l}\text { Andrade e Corrar (2008), Guney (2009), Monteiro, Almeida e Vasconcelos } \\
\text { (2012), Miranda et al. (2015) e Ferreira (2015) }\end{array}$ \\
\hline & Horas de Estudo & $\begin{array}{l}\text { Andrade e Corrar (2008), Souza (2008), Guney (2009), Paiva e Lourenço } \\
\text { (2011), Santos (2012), Miranda et al. (2015), Moura, Miranda e Pereira } \\
\text { (2015), Ferreira (2015), Andrietti e Velasco (2015), Rangel e Miranda } \\
\text { (2016) e Rodrigues et al. (2016) }\end{array}$ \\
\hline & Horas de Sono & $\begin{array}{l}\text { Burrus e Graham (2009), Miranda et al. (2015) e Haile, Alemu e Hablewold } \\
(2017)\end{array}$ \\
\hline & $\begin{array}{l}\text { Comportamentais } \\
\text { (Motivação e Nível de } \\
\text { Ansiedade) }\end{array}$ & $\begin{array}{l}\text { Campbell (2007), Monteiro, Almeida e Vasconcelos (2012), Miranda et al. } \\
\text { (2015), Moura, Miranda e Pereira (2015) e Rangel e Miranda (2016) }\end{array}$ \\
\hline & $\begin{array}{l}\text { Participação em } \\
\text { Projetos de Iniciação } \\
\text { Científica, Pesquisa ou } \\
\text { Extensão }\end{array}$ & $\begin{array}{l}\text { Andrade e Corrar (2008), Cornachione Júnior et al. (2010), Santos (2012), } \\
\text { Lepp, Barkley e Karpinski (2014), Moura, Miranda e Pereira (2015) e } \\
\text { Rodrigues et al. (2016) }\end{array}$ \\
\hline \multirow{5}{*}{ IES } & Ambiente de Estudo & $\begin{array}{l}\text { Campbell (2007), Cruz, Corrar e Slomski (2008), Miranda et al. (2015) e } \\
\text { Ferreira (2015) }\end{array}$ \\
\hline & $\begin{array}{l}\text { Frequência de } \\
\text { utilização da Biblioteca }\end{array}$ & $\begin{array}{l}\text { Andrade e Corrar (2008), Cruz, Corrar e Slomski (2008), Moura, Miranda e } \\
\text { Pereira (2015), Ferreira (2015) e Rodrigues et al. (2016) }\end{array}$ \\
\hline & Tamanho da Turma & $\begin{array}{l}\text { Harrington et al. (2006), Andrade e Corrar (2008), Guney (2009), Miranda } \\
\text { et al. (2015), Moura, Miranda e Pereira (2015) e Ferreira (2015) }\end{array}$ \\
\hline & $\begin{array}{l}\text { Horário da Disciplina } \\
\text { (Turno) }\end{array}$ & $\begin{array}{l}\text { Barros et al. (2001), Cornachione Júnior et al. (2010), Miranda et al. (2015) } \\
\text { e Ferreira (2015) }\end{array}$ \\
\hline & Forma de Ingresso & Miranda et al. (2015), Ferreira (2015) e Rodrigues et al. (2016) \\
\hline
\end{tabular}

Fonte: Elaborado pelos autores (2017). 
qualificação pedagógica e estratégia ou método de ensino). Das quatorze variáveis relacionadas à dimensão corpo docente, somente duas delas não apresentaram significância de acordo com as pesquisas analisadas (idade e participação em projetos de iniciação científica, pesquisa ou extensão). Na dimensão IES, verificou-se que três das cinco variáveis estudadas mostraram-se significativas em relação ao desempenho (ambiente de estudo, tamanho da turma e forma de ingresso). Portanto, ao considerar as três dimensões, a literatura aponta que 17, das 23 variáveis, são significativas em relação ao desempenho acadêmico, embora os achados tenham sido conduzidos sob perspectivas teórica e empírica distintas.

Para orientar o método de investigação e responder à pergunta de pesquisa, expõe-se as seguintes hipóteses a serem testadas:

Hipótese 1: As variáveis concernentes à dimensão corpo docente possuem relação com a variável desempenho acadêmico dos alunos de graduação em Ciências Contábeis.

Hipótese 2: As variáveis concernentes à dimensão corpo discente possuem relação com a variável desempenho acadêmico dos alunos de graduação em Ciências Contábeis.

Hipótese 3: As variáveis concernentes à dimensão IES possuem relação com a variável desempenho acadêmico dos alunos de graduação em Ciências Contábeis.

\section{PROCEDIMENTOS METODOLÓGICOS}

Este estudo é classificado como quantitativo em função da utilização de técnicas estatísticas e descritivo decorrente do objetivo geral. Em relação aos procedimentos, classifica-se como pesquisa de levantamento por conta da aplicação de questionário e também como documental, devido ao uso de documentos como fonte de dados.

Como população desta pesquisa, considerou-se os 617 alunos do segundo ao oitavo períodos do curso de Ciências Contábeis, matriculados no segundo semestre de 2016 e distribuídos em dois campi de uma universidade comunitária do estado de Santa Catarina (179 alunos do campus A e 438 do campus B). Destes, obteve-se uma amostra de 361 respondentes, representando 58,51\% da população pesquisada (116 do campus A e 245 do campus B).

A pesquisa de levantamento se deu por meio de um questionário com vinte questões fechadas, adaptado dos trabalhos de Andrade e Corrar (2008), Souza (2008) e Ferreira (2015), validado por três professores da área e realizado pré-teste com alunos do primeiro período, para obter informações junto aos discentes das variáveis concernentes ao desempenho acadêmico relacionadas às dimensões corpo docente, corpo discente e IES. A aplicação do questionário ocorreu entre 21 de setembro e 5 de outubro de 2016. Ressalta-se que no momento da aplicação, foi solicitado que os alunos se identificassem no questionário (nome e número de matrícula) para que posteriormente, fosse possível acessar o coeficiente de rendimento de cada discente.

A pesquisa documental ocorreu por meio de acesso ao sistema acadêmico da IES para coleta do coeficiente de rendimento dos discentes, como forma de mensuração da variável desempenho acadêmico. É importante ressaltar que os respondentes se identificavam no questionário com nome e número de matrícula para que fosse possível confrontar as respostas com o desempenho. Além disto, também foram obtidas informações para as variáveis titulação, qualificação pedagógica, experiência profissional e tamanho da turma diretamente com os coordenadores de cada curso, que repassaram as informações referentes à titulação, horas de formação continuada e tempo de experiência profissional de cada docente, assim como a quantidade de alunos em cada turma. Esta coleta ocorreu entre 10 de outubro e 7 de novembro de 2016. 
RELAÇÃO DAS VARIÁVEIS CONCERNENTES AO DESEMPENHO ACADÊMICO: UM ESTUDO COM ALUNOS DE GRADUAÇÃO EM CIÊNCIAS CONTÁBEIS

Quadro 4 - Forma de mensuração das variáveis

\begin{tabular}{|c|c|c|c|}
\hline Dimensão & Variáveis & Forma de Mensuração & $\begin{array}{c}\text { Autores } \\
\end{array}$ \\
\hline \multicolumn{2}{|c|}{ Desempenho Acadêmico } & $\begin{array}{l}\text { Coeficiente de Rendimento Acadêmico } \\
\text { (Escala de } 0 \text { a 10) }\end{array}$ & $\begin{array}{c}\text { Burrus e Graham (2009); Soares e } \\
\text { Barbedo (2013); Lepp, Barkley e } \\
\text { Karpinski (2014); Mamede et al. } \\
\text { (2015); Moura, Miranda e Pereira } \\
\text { (2015); Andrietti e Velasco (2015); } \\
\text { Rangel e Miranda (2016); } \\
\text { Mehmood, Sadaf e Kousar (2017); } \\
\text { Zaidi et al. (2017); Haile, Alemu e } \\
\text { Hablewold (2017); Smirnov e } \\
\text { Thurner (2017) }\end{array}$ \\
\hline \multirow{4}{*}{$\begin{array}{l}\text { Corpo } \\
\text { Docente }\end{array}$} & Titulação & $\begin{array}{c}0 \text { (especialização e mestrado) e } 1 \\
\text { (doutorado) }\end{array}$ & $\begin{array}{c}\text { Santos (2012); Rodrigues et al. } \\
\text { (2016) }\end{array}$ \\
\hline & $\begin{array}{l}\text { Qualificação } \\
\text { Pedagógica }\end{array}$ & $\begin{array}{c}0 \text { (não fez formação continuada) e } 1 \\
\text { (fez uma ou mais horas de formação) }\end{array}$ & $\begin{array}{c}\text { Santos (2012); Rodrigues et al. } \\
\text { (2016) }\end{array}$ \\
\hline & $\begin{array}{l}\text { Experiência } \\
\text { Profissional } \\
\end{array}$ & $\begin{array}{c}0 \text { (não trabalha na área) e } 1 \text { (trabalha um } \\
\text { ano ou mais na área) }\end{array}$ & Santos (2012) \\
\hline & $\begin{array}{c}\text { Estratégia ou } \\
\text { Método de Ensino } \\
\end{array}$ & $\begin{array}{c}0 \text { (aulas expositivas) e } 1 \text { (aulas } \\
\text { práticas/trabalhos em grupo/outros) }\end{array}$ & Santos (2012) \\
\hline \multirow{14}{*}{$\begin{array}{l}\text { Corpo } \\
\text { Discente }\end{array}$} & Gênero & 0 (feminino) e 1 (masculino) & $\begin{array}{l}\text { Santos (2012); Ferreira (2015); } \\
\text { Rodrigues et al. (2016) }\end{array}$ \\
\hline & Idade & 0 (até 30 anos) e 1 (mais de 30 anos) & $\begin{array}{l}\text { Santos (2012); Ferreira (2015); } \\
\text { Rodrigues et al. (2016) }\end{array}$ \\
\hline & Etnia & $\begin{array}{c}0 \text { (brancos/amarelos) e } 1 \\
\text { (negros/pardos/indígenas) }\end{array}$ & $\begin{array}{l}\text { Santos (2012); Ferreira (2015); } \\
\text { Rodrigues et al. (2016) }\end{array}$ \\
\hline & $\begin{array}{c}\text { Status } \\
\text { Socioeconômico }\end{array}$ & $\begin{array}{l}0 \text { (até } 4,5 \text { salários mínimos por pessoa) } \\
\text { e } 1 \text { (acima de } 4,5 \text { salários mínimos por } \\
\text { pessoa) }\end{array}$ & $\begin{array}{l}\text { Santos (2012); Ferreira (2015); } \\
\text { Rodrigues et al. (2016) }\end{array}$ \\
\hline & $\begin{array}{l}\text { Escolaridade dos } \\
\text { Pais } \\
\end{array}$ & $\begin{array}{l}0 \text { (de nenhuma a ensino médio) e } 1 \\
\text { (ensino superior ou pós-graduação) }\end{array}$ & $\begin{array}{l}\text { Santos (2012); Ferreira (2015); } \\
\text { Rodrigues et al. (2016) }\end{array}$ \\
\hline & Estado Civil & $\begin{array}{l}0 \text { (solteiro) e } 1 \text { (casado/separado/união } \\
\text { estável/viúvo/outro); }\end{array}$ & $\begin{array}{l}\text { Santos (2012); Ferreira (2015); } \\
\text { Rodrigues et al. (2016) }\end{array}$ \\
\hline & Número de Filhos & 0 (nenhum) e 1 (1 ou mais) & Santos (2012) \\
\hline & Absenteísmo & $\begin{array}{l}0 \text { (até } 10 \text { faltas a cada semestre) e } 1 \\
\text { (acima de } 10 \text { faltas a cada semestre) }\end{array}$ & Miranda et al. (2015) \\
\hline & $\begin{array}{l}\text { Desempenho } \\
\text { Escolar Anterior }\end{array}$ & $\begin{array}{l}0 \text { (sempre fui aprovado com/sem } \\
\text { recuperação) e } 1 \text { (já reprovei em uma } \\
\text { disciplina ou mais) }\end{array}$ & $\begin{array}{l}\text { Ferreira (2015); Rodrigues et al. } \\
\text { (2016) }\end{array}$ \\
\hline & $\begin{array}{l}\text { Atividade } \\
\text { Remunerada }\end{array}$ & $\begin{array}{c}0 \text { (não trabalha/faz estágio ou faz } \\
\text { eventualmente) e } 1 \text { (trabalha/faz } \\
\text { estágio) }\end{array}$ & Ferreira (2015) \\
\hline & Horas de Estudo & $\begin{array}{c}0 \text { (não dedica horas de estudo fora de } \\
\text { sala) e } 1 \text { (dedica uma ou mais horas de } \\
\text { estudo) }\end{array}$ & $\begin{array}{l}\text { Santos (2012); Ferreira (2015); } \\
\text { Rodrigues et al. (2016) }\end{array}$ \\
\hline & Horas de Sono & $\begin{array}{l}0 \text { (dorme até } 6 \text { horas por noite) e } 1 \\
\text { (dorme mais que } 6 \text { horas por noite) }\end{array}$ & Miranda et al. (2015) \\
\hline & $\begin{array}{l}\text { Comportamentais } \\
\text { (Motivação e Nível } \\
\text { de Ansiedade) }\end{array}$ & $\begin{array}{l}\text { Motivação = } 0 \text { (muito baixa, baixa ou } \\
\text { nem baixa e nem alta) e } 1 \text { (alta ou muito } \\
\text { alta); Nível de Ansiedade }=0 \text { (muito } \\
\text { baixo, baixo ou nem baixo nem alto) e } 1 \\
\text { (alto ou muito alto) }\end{array}$ & Miranda et al. (2015) \\
\hline & $\begin{array}{l}\text { Participação em } \\
\text { Projetos de } \\
\text { Iniciação } \\
\text { Científica, Pesquisa } \\
\text { ou Extensão } \\
\end{array}$ & $\begin{array}{c}0 \text { (não participei de nenhuma atividade) } \\
\text { e } 1 \text { (participei de iniciação científica, } \\
\text { pesquisa ou extensão) }\end{array}$ & $\begin{array}{l}\text { Santos (2012); Ferreira (2015); } \\
\text { Rodrigues et al. (2016) }\end{array}$ \\
\hline
\end{tabular}


Continuação...

\begin{tabular}{|c|c|c|c|}
\hline Dimensão & Variáveis & Forma de Mensuração & Autores \\
\hline \multirow{5}{*}{ IES } & $\begin{array}{l}\text { Ambiente de } \\
\text { Estudo }\end{array}$ & $\begin{array}{l}0 \text { (não frequenta ou frequenta menos de } \\
\text { duas vezes por semana) e } 1 \text { (frequenta } \\
\text { pelo menos duas vezes por semana) }\end{array}$ & Rodrigues et al. (2016) \\
\hline & $\begin{array}{c}\text { Frequência de } \\
\text { utilização da } \\
\text { Biblioteca }\end{array}$ & $\begin{array}{l}0 \text { (não frequenta ou frequenta menos de } \\
\text { duas vezes por semana) e } 1 \text { (frequenta } \\
\text { pelo menos duas vezes por semana) }\end{array}$ & Ferreira (2015) \\
\hline & Tamanho da Turma & $\begin{array}{c}0 \text { (até } 40 \text { alunos) e } 1 \text { (acima de } 40 \\
\text { alunos) }\end{array}$ & $\begin{array}{c}\text { Ferreira (2015); Rodrigues et al. } \\
\text { (2016) }\end{array}$ \\
\hline & $\begin{array}{c}\text { Horário da } \\
\text { Disciplina (Turno) }\end{array}$ & 0 (matutino) e 1 (noturno) & Ferreira (2015) \\
\hline & Forma de Ingresso & $\begin{array}{c}0 \text { (vestibular/processo seletivo) e } 1 \\
\text { (ProUni/bolsa oferecida pelo governo) }\end{array}$ & $\begin{array}{c}\text { Ferreira (2015); Rodrigues et al. } \\
\text { (2016) }\end{array}$ \\
\hline
\end{tabular}

Fonte: Elaborado pelos autores (2017).

Para a análise dos dados, inicialmente foi necessário unir as informações obtidas nas pesquisas de levantamento e documental. Para isto, estes dados foram organizados por meio do software Microsoft Excel@. Além disto, os dados advindos da pesquisa de levantamento (questões 1 a 19) e da pesquisa documental, estavam em escala nominal ou ordinal, e assim, foram transformados em valores numéricos. Neste contexto, foi feita a construção de variáveis dummy a partir destes dados, seguindo os trabalhos de Santos (2012), Miranda et al. (2015), Ferreira (2015) e Rodrigues et al. (2016), como é detalhado no Quadro 4.

Ressalta-se que a questão 20 do instrumento de coleta buscou identificar, na percepção dos alunos, a contribuição de cada uma das variáveis estudadas no desempenho acadêmico, por meio de uma escala com pontos de 0 a 10 , sendo 0 para nenhuma contribuição e 10 para total contribuição, com exceção da variável desempenho acadêmico, que foi obtida por meio da pesquisa documental.

A técnica escolhida para medir a confiabilidade do instrumento foi o coeficiente Alfa de Cronbach e para testar se os dados apresentam distribuição normal, aplicou-se a prova KolmogorovSmirnov. No que diz respeito à identificação da relação das variáveis com o desempenho acadêmico, foi efetuado o coeficiente de correlação ponto-bisserial e para a identificação da contribuição das variáveis no desempenho acadêmico, utilizou-se a correlação de Spearman. Para analisar a força de associação do coeficiente de correlação foram utilizados os valores que constam no Quadro 5.

Quadro 5 - Regras sobre o valor do coeficiente de correlação

\begin{tabular}{|c|c|}
\hline Variação do coeficiente* & Força de associação \\
\hline $0,91-1,00$ & Muito forte \\
\hline $0,71-0,90$ & Alta \\
\hline $0,41-0,70$ & Moderada \\
\hline $0,21-0,40$ & Pequena, mas definida \\
\hline $0,01-0,20$ & Leve, quase imperceptível \\
\hline$*$ Supõe que o coeficiente de correlação seja estatisticamente significativo. \\
\hline
\end{tabular}

Fonte: Adaptado de Hair Jr. et al. (2005).

É importante ressaltar que para a classificação das variáveis significativas, considerou-se um erro amostral de $5 \%$.

\section{ANÁLISE DOS RESULTADOS}

Para iniciar a análise dos dados, apresenta-se a análise descritiva da distribuição dos alunos por campus e o período em que estão matriculados. Para isto, a Tabela 1 demonstra a distribuição dos respondentes por período e campus. 

ALUNOS DE GRADUAÇÃO EM CIÊNCIAS CONTÁBEIS

Tabela 1 - Distribuição dos respondentes por período

\begin{tabular}{|c|c|c|c|c|c|c|c|c|}
\hline \multicolumn{3}{|c|}{ Ciências Contábeis - Campus A } & \multicolumn{3}{|c|}{ Ciências Contábeis - Campus B } & \multicolumn{3}{|c|}{ Ciências Contábeis - Total } \\
\hline Período & Freq. & Percentual & Período & Freq. & Percentual & Período & Freq. & Percentual \\
\hline $2^{\circ}$ & 15 & $12,93 \%$ & $2^{\circ}$ & 59 & $24,08 \%$ & $2^{\circ}$ & 74 & $20,50 \%$ \\
\hline $3^{\circ}$ & 18 & $15,52 \%$ & $3^{\circ}$ & 25 & $10,20 \%$ & $3^{\circ}$ & 43 & $11,91 \%$ \\
\hline $4^{\circ}$ & 18 & $15,52 \%$ & $4^{\circ}$ & 46 & $18,78 \%$ & $4^{\circ}$ & 64 & $17,73 \%$ \\
\hline $5^{\circ}$ & 10 & $8,62 \%$ & $5^{\circ}$ & 12 & $4,90 \%$ & $5^{\circ}$ & 22 & $6,09 \%$ \\
\hline $6^{\circ}$ & 23 & $19,83 \%$ & $6^{\circ}$ & 52 & $21,22 \%$ & $6^{\circ}$ & 75 & $20,78 \%$ \\
\hline $7^{\circ}$ & 6 & $5,17 \%$ & $7^{\circ}$ & 18 & $7,35 \%$ & $7^{\circ}$ & 24 & $6,65 \%$ \\
\hline $8^{\circ}$ & 26 & $22,41 \%$ & $8^{\circ}$ & 33 & $13,47 \%$ & $8^{\circ}$ & 59 & $16,34 \%$ \\
\hline Total & 116 & $32,13 \%$ & Total & 245 & $67,87 \%$ & Total & 361 & $100,00 \%$ \\
\hline
\end{tabular}

Fonte: Dados da Pesquisa (2017).

No que diz respeito aos períodos em que os alunos estão matriculados com os dados consolidados, destacam-se o sexto período, com $20,78 \%$ e o segundo período, com 20,50\%. Os menores percentuais de participação foram do quinto e sétimo períodos, com apenas 6,09\% e 6,65\% respectivamente. Além disto, observa-se maior representatividade na amostra dos respondentes do campus B, correspondendo a $67,87 \%$ da amostra total, seguindo a tendência da população deste estudo.

Para mensurar o nível de confiabilidade do instrumento de coleta de dados, escolheu-se o Alfa de Cronbach, conforme apresenta-se a seguir.

Tabela 2 - Alfa de Cronbach

\begin{tabular}{cc}
\hline Alfa de Cronbach & Número de casos \\
\hline 0,796 & 361 \\
\hline Fonte: &
\end{tabular}

Fonte: Dados da Pesquisa (2017).

Tabela 3 - Teste de Kolmogorov-Smirnov

\begin{tabular}{|c|c|c|c|c|}
\hline & \multirow{2}{*}{ Variáveis } & \multicolumn{3}{|c|}{ Kolmogorov-Smirnov } \\
\hline & & Estatística & df & Sig. \\
\hline \multirow{4}{*}{$\begin{array}{l}\text { Corpo } \\
\text { Docente }\end{array}$} & Titulação & 0,172 & 361 & 0,000 \\
\hline & Qualificação Pedagógica & 0,167 & 361 & 0,000 \\
\hline & Experiência Profissional & 0,192 & 361 & 0,000 \\
\hline & Estratégia ou Método de Ensino & 0,226 & 361 & 0,000 \\
\hline \multirow{15}{*}{$\begin{array}{l}\text { Corpo } \\
\text { Discente }\end{array}$} & Gênero & 0,407 & 361 & 0,000 \\
\hline & Idade & 0,139 & 361 & 0,000 \\
\hline & Etnia & 0,481 & 361 & 0,000 \\
\hline & Status Socioeconômico & 0,223 & 361 & 0,000 \\
\hline & Escolaridade dos Pais & 0,295 & 361 & 0,000 \\
\hline & Estado Civil & 0,184 & 361 & 0,000 \\
\hline & Número de Filhos & 0,179 & 361 & 0,000 \\
\hline & Absenteísmo & 0,165 & 361 & 0,000 \\
\hline & Desempenho Escolar Anterior & 0,121 & 361 & 0,000 \\
\hline & Atividade Remunerada & 0,149 & 361 & 0,000 \\
\hline & Horas de Estudo & 0,201 & 361 & 0,000 \\
\hline & Horas de Sono & 0,193 & 361 & 0,000 \\
\hline & Comportamentais (Motivação) & 0,191 & 361 & 0,000 \\
\hline & Comportam. (Nível de Ansiedade) & 0,132 & 361 & 0,000 \\
\hline & $\begin{array}{l}\text { Participação em Iniciação Científica, Pesquisa ou } \\
\text { Extensão }\end{array}$ & 0,111 & 361 & 0,000 \\
\hline \multirow{5}{*}{ IES } & Ambiente de Estudo & 0,162 & 361 & 0,000 \\
\hline & Freq. de Utilização da Biblioteca & 0,111 & 361 & 0,000 \\
\hline & Tamanho da Turma & 0,130 & 361 & 0,000 \\
\hline & Horário da Disciplina (Turno) & 0,133 & 361 & 0,000 \\
\hline & Forma de Ingresso & 0,245 & 361 & 0,000 \\
\hline
\end{tabular}

Fonte: Dados da Pesquisa (2017). 
Conforme as informações extraídas do teste Kolmogorov-Smirnov, todas as variáveis apresentaram significância de 0,000, o que permite rejeitar a hipótese de nulidade. Sendo assim, os dados não apresentam uma distribuição normal, devendo ser aplicado a eles, técnicas estatísticas nãoparamétricas.

Neste contexto, apresenta-se os coeficientes de correlação ponto-bisserial das variáveis, divididos por dimensões. A primeira analisada foi a docente, conforme mostra-se na Tabela 4.

Tabela 4 - Correlação para a dimensão docente

\begin{tabular}{ccc}
\hline Variáveis & Correlação ponto-bisserial & Sig. (2 extremidades) \\
\hline Titulação & 0,255 & 0,063 \\
Qualificação Pedagógica & 0,076 & 0,583 \\
Experiência Profissional & 0,152 & 0,271 \\
Estratégia ou Método de Ensino & $-0,123^{*}$ & 0,019 \\
\hline
\end{tabular}

* A correlação é significativa no nível 0,05 (2 extremidades).

$\mathrm{N}=54$. Na variável Estratégia ou Método de Ensino, $\mathrm{N}=361$.

Fonte: Dados da Pesquisa (2017).

Com base nestes dados, a correlação entre a dimensão docente e o desempenho acadêmico é demonstrada no Quadro 6.

Quadro 6 - Correlação entre a dimensão docente e o desempenho acadêmico

\begin{tabular}{|c|c|c|c|}
\hline Variáveis & $\begin{array}{c}\text { Força de } \\
\text { Associação }\end{array}$ & $\begin{array}{c}\text { Interpretação dos } \\
\text { Resultados }\end{array}$ & Teoria \\
\hline Titulação & Sem força & Sem significância & $\begin{array}{l}\text { Os resultados corroboram com Ferreira } \\
\text { (2015) e se opõem aos de Zonatto et al. } \\
\text { (2013), Miranda, Casanova e Cornachione } \\
\text { Júnior (2013), Miranda et al. (2015) e } \\
\text { Lemos e Miranda (2015). }\end{array}$ \\
\hline Qualificação Pedagógica & Sem força & Sem significância & $\begin{array}{l}\text { Os resultados discordam de Guney (2009) e } \\
\text { Miranda, Casanova e Cornachione Júnior } \\
\text { (2013) e estão em concordância com } \\
\text { Nascimento (2005) e Miranda (2011). }\end{array}$ \\
\hline Experiência Profissional & Sem força & Sem significância & $\begin{array}{l}\text { Confirma-se os resultados de Nascimento } \\
\text { (2005), Miranda (2011), Miranda, } \\
\text { Casanova e Cornachione Júnior (2013) e } \\
\text { Miranda et al. (2015). }\end{array}$ \\
\hline $\begin{array}{l}\text { Estratégia ou Método de } \\
\text { Ensino }\end{array}$ & Leve & $\begin{array}{l}\text { Aulas expositivas } \\
\text { fazem com que os } \\
\text { alunos obtenham um } \\
\text { melhor desempenho } \\
\text { acadêmico }\end{array}$ & $\begin{array}{c}\text { Com exceção dos achados de Moura, } \\
\text { Miranda e Pereira (2015), os resultados } \\
\text { corroboram com Andrade e Corrar (2008), } \\
\text { Cruz, Corrar e Slomski (2008) e Miranda et } \\
\text { al. (2015). }\end{array}$ \\
\hline
\end{tabular}

Fonte: Dados da Pesquisa (2017).

Dentre as variáveis classificadas na dimensão docente, a estratégia ou método de ensino foi a única que apresentou relação com o desempenho acadêmico, com força de associação leve. Verificase que com exceção do estudo de Moura, Miranda e Pereira (2015) que não apresentou significância para a variável, este resultado vai ao encontro dos trabalhos de Andrade e Corrar (2008), Cruz, Corrar e Slomski (2008) e Miranda et al. (2015), que também observaram uma relação com a variável desempenho acadêmico. Desta forma, é possível perceber que a estratégia ou método de ensino adotado pelo professor em sala pode refletir no desempenho acadêmico de seu aluno.

Sendo assim, a Hipótese 1: as variáveis concernentes à dimensão docente possuem relação com a variável desempenho acadêmico dos alunos de graduação em Ciências Contábeis não foi aceita. Porém, dentre as variáveis desta dimensão, é relevante destacar que a estratégia ou método de ensino possui relação (leve) com o desempenho acadêmico. A seguir, na Tabela 5, os resultados obtidos para a dimensão discente. 
Tabela 5 - Correlação para a dimensão discente

\begin{tabular}{ccc}
\hline Variáveis & Correlação ponto-bisserial & Sig. (2 extremidades) \\
\hline Gênero & $-0,059$ & 0,263 \\
Idade & 0,015 & 0,774 \\
Etnia & 0,034 & 0,516 \\
Status Socioeconômico & $-0,161^{* *}$ & 0,002 \\
Escolaridade da Mãe & $-0,015$ & 0,779 \\
Escolaridade do Pai & 0,052 & 0,326 \\
Estado Civil & 0,001 & 0,991 \\
Número de Filhos & 0,092 & 0,082 \\
Absenteísmo & $-0,142^{* *}$ & 0,007 \\
Desempenho Escolar Anterior & $-0,298^{* *}$ & 0,000 \\
Atividade Remunerada & $-0,013$ & 0,807 \\
Horas de Estudo & $0,125^{*}$ & 0,018 \\
Horas de Sono & 0,043 & 0,421 \\
Motivação & $0,226^{* *}$ & 0,000 \\
Nível de Ansiedade & 0,030 & 0,564 \\
Partic. Inic. Cient., Pesq. ou Extensão & $-0,012$ & 0,820 \\
\hline
\end{tabular}

** A correlação é significativa no nível 0,01. * A correlação é significativa no nível 0,05 (2 extremidades).

$\mathrm{N}=361$.

Fonte: Dados da Pesquisa (2017).

Desta forma, apresenta-se no Quadro 7, a correlação entre a dimensão discente e o desempenho acadêmico.

Quadro 7 - Correlação entre a dimensão discente e o desempenho acadêmico

\begin{tabular}{|c|c|c|c|}
\hline Variáveis & $\begin{array}{c}\text { Força de } \\
\text { Associação }\end{array}$ & $\begin{array}{l}\text { Interpretação dos } \\
\text { Resultados }\end{array}$ & Teoria \\
\hline Gênero & Sem força & Sem significância & $\begin{array}{l}\text { Os achados corroboram com Guney (2009) e Soares e } \\
\text { Barbedo (2013). Discordam de Cornachione Júnior et al. } \\
\text { (2010), Ballester (2012), Araújo et al. (2013), Mamede et } \\
\text { al. (2015) e Rangel e Miranda (2016). }\end{array}$ \\
\hline Idade & Sem força & Sem significância & $\begin{array}{l}\text { Os resultados confirmam os trabalhos de Cornachione } \\
\text { Júnior et al. (2010), Ballester (2012), Soares e Barbedo } \\
\text { (2013), Ferreira (2015) e Rodrigues et al. (2016) e se } \\
\text { opõem aos de Diaz (2007), Guney (2009), Santos (2012), } \\
\text { Araújo et al. (2013) e Mamede et al. (2015). }\end{array}$ \\
\hline Etnia & Sem força & Sem significância & $\begin{array}{l}\text { Divergindo de Eikner e Montondon (2001), Santos (2012), } \\
\text { Ferreira (2015) e Rodrigues et al. (2016), os resultados } \\
\text { corroboram com o trabalho de Keef e Roush (1997). }\end{array}$ \\
\hline $\begin{array}{c}\text { Status } \\
\text { Socioeconômico }\end{array}$ & Leve & $\begin{array}{l}\text { Alunos com menor } \\
\text { renda possuem um } \\
\text { melhor desempenho } \\
\text { acadêmico }\end{array}$ & $\begin{array}{c}\text { Os achados concordam com toda a teoria pesquisada, } \\
\text { como Diaz (2007), Andrade e Corrar (2008), Souza } \\
\text { (2008), Santos (2012), Miranda et al. (2015), Ferreira } \\
\text { (2015) e Rodrigues et al. (2016). }\end{array}$ \\
\hline $\begin{array}{l}\text { Escolaridade } \\
\text { dos Pais }\end{array}$ & Sem força & Sem significância & $\begin{array}{l}\text { Estes resultados corroboram com os apresentados por } \\
\text { Miranda et al. (2015), Lemos e Miranda (2015), Moura, } \\
\text { Miranda e Pereira (2015) e Rodrigues et al. (2016) e se } \\
\text { opõem aos encontrados por Andrade e Corrar (2008), } \\
\text { Souza (2008), Santos (2012) e Ferreira (2015). }\end{array}$ \\
\hline Estado Civil & Sem força & Sem significância & $\begin{array}{c}\text { Confirmam os trabalhos de Masasi (2012), Miranda et al. } \\
\text { (2015) e Mamede et al. (2015) e de maneira distinta aos } \\
\text { autores Andrade e Corrar (2008), Santos (2012), Ferreira } \\
\text { (2015) e Rodrigues et al. (2016). }\end{array}$ \\
\hline $\begin{array}{l}\text { Número de } \\
\text { Filhos }\end{array}$ & Sem força & Sem significância & $\begin{array}{l}\text { Os achados seguem os estudos de Santos (2012) e Ferreira } \\
\text { (2015) e contrapõem os de Masasi (2012) e Miranda et al. } \\
\text { (2015). }\end{array}$ \\
\hline
\end{tabular}




\begin{tabular}{|c|c|c|c|}
\hline Variáveis & $\begin{array}{c}\text { Força de } \\
\text { Associação }\end{array}$ & $\begin{array}{l}\text { Interpretação dos } \\
\text { Resultados }\end{array}$ & Teoria \\
\hline Absenteísmo & Leve & $\begin{array}{l}\text { Quanto menos os } \\
\text { alunos faltarem, } \\
\text { melhor será seu } \\
\text { desempenho }\end{array}$ & $\begin{array}{l}\text { Os resultados corroboram com Guney (2009), Miranda et } \\
\text { al. (2015) e Moura, Miranda e Pereira (2015). }\end{array}$ \\
\hline $\begin{array}{l}\text { Desempenho } \\
\text { Escolar Anterior }\end{array}$ & Pequena & $\begin{array}{l}\text { Alunos que não } \\
\text { reprovaram antes do } \\
\text { ingresso ao ensino } \\
\text { superior, apresentam } \\
\text { melhor desempenho }\end{array}$ & $\begin{array}{c}\text { Também chegaram a este resultado, as pesquisas de } \\
\text { Souza (2008), Guney (2009), Ballester (2012), Miranda } \\
\text { et al. (2015) e Ferreira (2015). }\end{array}$ \\
\hline $\begin{array}{l}\text { Atividade } \\
\text { Remunerada }\end{array}$ & Sem força & Sem significância & $\begin{array}{l}\text { Os resultados corroboram com os estudos de Ferreira } \\
\text { (2015) e Rodrigues et al. (2016) e discordam de Andrade } \\
\text { e Corrar (2008) e Guney (2009). }\end{array}$ \\
\hline Horas de Estudo & Leve & $\begin{array}{l}\text { O aluno que dedica } \\
\text { pelo menos uma hora } \\
\text { semanal aos estudos, } \\
\text { possui um melhor } \\
\text { desempenho } \\
\text { acadêmico }\end{array}$ & $\begin{array}{l}\text { Estes resultados discordam somente do autor Guney } \\
\text { (2009). Concordam com Andrade e Corrar (2008), Souza } \\
\text { (2008), Santos (2012), Moura, Miranda e Pereira (2015), } \\
\text { Ferreira (2015), Andrietti e Velasco (2015), Rangel e } \\
\text { Miranda (2016) e Rodrigues et al. (2016). }\end{array}$ \\
\hline Horas de Sono & Sem força & Sem significância & $\begin{array}{l}\text { Os achados contradizem o que enfatizam os autores } \\
\text { Burrus e Graham (2009) e Miranda et al. (2015) e vão ao } \\
\text { encontro de Haile, Alemu e Hablewold. }\end{array}$ \\
\hline Motivação & Pequena & $\begin{array}{l}\text { Alunos com motivação } \\
\text { alta ou muito alta } \\
\text { possuem um melhor } \\
\text { desempenho }\end{array}$ & $\begin{array}{l}\text { Estes achados corroboram com as pesquisas de Campbell } \\
\text { (2007), Moura, Miranda e Pereira (2015), Miranda et al. } \\
\text { (2015) e Rangel e Miranda (2016). }\end{array}$ \\
\hline $\begin{array}{c}\text { Nível de } \\
\text { Ansiedade }\end{array}$ & Sem força & Sem significância & $\begin{array}{l}\text { Os resultados discordam de Campbell (2007) e Miranda } \\
\text { et al. (2015). }\end{array}$ \\
\hline $\begin{array}{l}\text { Part. Inic. } \\
\text { Cient., Pesq. ou } \\
\text { Extensão }\end{array}$ & Sem força & Sem significância & $\begin{array}{c}\text { Os achados seguem a tendência de Cornachione Júnior et } \\
\text { al. (2010), Santos (2012), Moura, Miranda e Pereira } \\
\text { (2015) e Rodrigues et al. (2016). }\end{array}$ \\
\hline
\end{tabular}

Fonte: Dados da Pesquisa (2017).

Tratando-se das variáveis classificadas na dimensão discente, as que apresentaram relação com o desempenho acadêmico foram status socioeconômico (força leve), absenteísmo (força leve), desempenho escolar anterior (força pequena), horas de estudo (força leve) e motivação (força pequena).

Desta forma, o resultado observado para a variável status socioeconômico está de acordo com a literatura pesquisada, cujos estudos concluíram que esta variável possui relação com o desempenho acadêmico, segundo Diaz (2007), Andrade e Corrar (2008), Souza (2008), Santos (2012), Miranda et al. (2015), Ferreira (2015) e Rodrigues et al. (2015), ou seja, a renda familiar do aluno pode afetar seu desempenho acadêmico.

A relação da variável absenteísmo com o desempenho acadêmico, corrobora com os trabalhos selecionados na literatura de Guney (2009), Miranda et al. (2015) e Moura, Miranda e Pereira (2015), sendo que seus achados também evidenciaram significância para a variável em questão. Neste contexto, enfatiza-se que o acadêmico faltar às aulas pode influenciar em suas notas. Da mesma forma, a variável desempenho escolar anterior também foi ao encontro dos resultados obtidos pela literatura pesquisada, que apontaram a variável como significante em relação ao desempenho acadêmico, conforme Souza (2008), Guney (2009), Ballester (2012), Miranda et al. (2015) e Ferreira (2015), ou seja, as notas obtidas pelo aluno antes de seu ingresso na universidade também pode impactar em seu desempenho acadêmico.

Tratando-se da variável horas de estudo, percebe-se que a quantidade de tempo que o acadêmico estuda, pode influenciar sua performance em sala de aula. Diferentemente do estudo de Guney (2009) que não encontrou significância para esta variável, este achado corrobora com os 
trabalhos de Andrade e Corrar (2008), Souza (2008), Santos (2012), Moura, Miranda e Pereira (2015), Andrietti e Velasco (2015), Rangel e Miranda (2016) e Rodrigues et al. (2016).

Por fim, a variável motivação também apresentou relação com o desempenho acadêmico, evidenciando que o nível de motivação apresentado pelos alunos pode influenciar seus desempenhos. Este achado vai ao encontro dos resultados apresentados por Campbell (2007), Moura, Miranda e Pereira (2015), Miranda et al. (2015) e Rangel e Miranda (2016).

Sendo assim, a Hipótese 2: as variáveis concernentes à dimensão discente possuem relação com a variável desempenho acadêmico dos alunos de graduação em Ciências Contábeis não foi aceita. Entretanto, embora a hipótese não tenha se confirmado, há variáveis que são significativas, como status socioeconômico, absenteísmo, desempenho escolar anterior, horas de estudo e motivação. Dentre estas variáveis, todas possuem força de associação leve ou pequena e possuem nível de significância de $1 \%$, com exceção da variável horas de estudo, cuja significância é de 5\%. Na Tabela 6, apresenta-se os resultados obtidos referentes à IES, que foi a terceira dimensão avaliada.

Tabela 6 - Correlação para a dimensão IES

\begin{tabular}{ccc}
\hline Variáveis & Correlação ponto-bisserial & Sig. (2 extremidades) \\
\hline Ambiente de Estudo & $0,118^{*}$ & 0,025 \\
Frequência de Utiliz. da Biblioteca & 0,063 & 0,231 \\
Tamanho da Turma & $-0,021$ & 0,696 \\
Horário da Disciplina (Turno) & $-0,047$ & 0,369 \\
Forma de Ingresso & $0,162^{* *}$ & 0,002 \\
\hline
\end{tabular}

** A correlação é significativa no nível 0,01. * A correlação é significativa no nível 0,05 (2 extremidades). $\mathrm{N}=361$.

Fonte: Dados da Pesquisa (2017). Quadro 8.

Com isto, a correlação entre a dimensão IES e o desempenho acadêmico é apresentada no

Quadro 8 - Correlação entre a dimensão discente e o desempenho acadêmico

\begin{tabular}{|c|c|c|c|}
\hline Variáveis & $\begin{array}{c}\text { Força de } \\
\text { Associação }\end{array}$ & Interpretação dos Resultados & Teoria \\
\hline $\begin{array}{c}\text { Ambiente de } \\
\text { Estudo }\end{array}$ & Leve & $\begin{array}{c}\text { Os alunos que utilizam o espaço para } \\
\text { estudos pelo menos duas vezes por } \\
\text { semana, possuem melhor desempenho. }\end{array}$ & $\begin{array}{c}\text { Os resultados corroboram com Campbell } \\
\text { (2007), Miranda et al. (2015) e Ferreira } \\
\text { (2015) e discordam de Cruz, Corrar e } \\
\text { Slomski (2008). }\end{array}$ \\
\hline $\begin{array}{c}\text { Freq. de } \\
\text { Utilização da } \\
\text { Biblioteca }\end{array}$ & Sem força & Sem significância. & $\begin{array}{c}\text { Os achados seguem o que afirmam } \\
\text { Andrade e Corrar (2008), Cruz, Corrar e } \\
\text { Slomski (2008), Moura, Miranda e Pereira } \\
\text { (2015), Ferreira (2015) e Rodrigues et al. } \\
\text { (2016). }\end{array}$ \\
\hline $\begin{array}{c}\text { Tamanho da } \\
\text { Turma }\end{array}$ & Sem força & Sem significância. & $\begin{array}{c}\text { Os resultados vão ao encontro das } \\
\text { pesquisas de Moura, Miranda e Pereira } \\
\text { (2015) e se opõem a Harrington et al. } \\
\text { (2006), Guney (2009) e Ferreira (2015). }\end{array}$ \\
\hline $\begin{array}{c}\text { Horário da } \\
\text { Disciplina } \\
\text { (Turno) }\end{array}$ & Sem força & $\begin{array}{c}\text { Os resultados confirmam os obtidos por } \\
\text { Cornachione Júnior et al. (2010) e Ferreira } \\
\text { (2015). }\end{array}$ \\
\hline $\begin{array}{c}\text { Forma de } \\
\text { Ingresso }\end{array}$ & Leve & $\begin{array}{c}\text { Alunos que ingressam por meio do } \\
\text { ProUni ou com bolsa oferecida pelo } \\
\text { governo, apresentam um melhor } \\
\text { desempenho acadêmico. }\end{array}$ & $\begin{array}{c}\text { Estes achados assemelham-se aos estudos } \\
\text { de Miranda et al. (2015) e Ferreira (2015). }\end{array}$ \\
\hline
\end{tabular}

Fonte: Dados da Pesquisa (2017).

Já na dimensão IES, as variáveis que se mostraram significativas em relação ao desempenho acadêmico foram o ambiente de estudo e a forma de ingresso, ambas com força de associação leve. 
Desta forma, no que diz respeito à variável ambiente de estudo, pode-se ressaltar que os acadêmicos que frequentam os espaços para estudo na IES podem ter seu desempenho acadêmico influenciado. Esta relação vai ao encontro dos estudos de Campbell (2007), Miranda et al. (2015) e Ferreira (2015) e discorda do resultado do trabalho Cruz, Corrar e Slomski (2008), que não observaram a variável em questão como significativa.

Tratando-se da variável forma de ingresso, enfatiza-se que a maneira como o aluno ingressa na IES (com ou sem bolsa de estudo) pode impactar em seu desempenho acadêmico, uma vez que estas variáveis apresentaram relação. Este achado corrobora com os estudos de Miranda et al. (2015) e Ferreira (2015).

Com isto, a Hipótese 3: As variáveis concernentes à dimensão IES possuem relação com a variável desempenho acadêmico dos alunos de graduação em Ciências Contábeis não foi aceita. Entretanto, algumas das variáveis desta dimensão são significantes, como ambiente de estudo e forma de ingresso. Nesta dimensão, todas as variáveis significativas possuem força de associação leve.

Para complementar esta análise, buscou-se identificar, na percepção dos alunos, a contribuição de cada uma das variáveis no seu desempenho acadêmico, a partir dos dados obtidos na questão 20 do questionário aplicado. Para isto, foi utilizado o coeficiente de correlação de Spearman, uma vez que os dados não apresentaram distribuição normal. Neste contexto, a Tabela 7 apresenta a correlação entre as dimensões docente, discente e IES e o desempenho acadêmico.

Tabela 7 - Correlação entre as dimensões docente, discente e IES e o desempenho acadêmico

\begin{tabular}{|c|c|c|c|}
\hline Variáveis & Dimensões & Correlação de Spearman & Sig. ( 2 extremidades) \\
\hline Titulação & \multirow{4}{*}{ Docente } & 0,028 & 0,592 \\
\hline Qualificação Pedagógica & & 0,092 & 0,083 \\
\hline Experiência Profissional & & 0,040 & 0,451 \\
\hline Estratégia ou Método de Ensino & & $0,123^{*}$ & 0,020 \\
\hline Gênero & \multirow{10}{*}{ Discente } & $-0,084$ & 0,110 \\
\hline Idade & & 0,045 & 0,390 \\
\hline Etnia & & $-0,092$ & 0,081 \\
\hline Status Socioeconômico & & $-0,001$ & 0,986 \\
\hline Escolaridade dos Pais & & $-0,043$ & 0,416 \\
\hline Estado Civil & & $-0,058$ & 0,271 \\
\hline Número de Filhos & & $-0,042$ & 0,425 \\
\hline Absenteísmo & & 0,053 & 0,317 \\
\hline Desempenho Escolar Anterior & & 0,100 & 0,057 \\
\hline Atividade Remunerada & & $-0,050$ & 0,346 \\
\hline Horas de Estudo & \multirow{5}{*}{ Discente } & 0,035 & 0,510 \\
\hline Horas de Sono & & $-0,010$ & 0,856 \\
\hline Motivação & & $0,113 *$ & 0,032 \\
\hline Nível de Ansiedade & & $-0,064$ & 0,224 \\
\hline Partic. Inic. Cient., Pesq. ou Extensão & & $-0,057$ & 0,279 \\
\hline Ambiente de Estudo & \multirow{5}{*}{ IES } & 0,091 & 0,085 \\
\hline Frequência de Utiliz. da Biblioteca & & 0,007 & 0,890 \\
\hline Tamanho da Turma & & 0,062 & 0,243 \\
\hline Horário da Disciplina (Turno) & & $-0,091$ & 0,083 \\
\hline Forma de Ingresso & & $-0,078$ & 0,138 \\
\hline
\end{tabular}

* A correlação é significativa no nível 0,05 (2 extremidades). $\mathrm{N}=361$.

Fonte: Dados da Pesquisa (2017).

A partir dos resultados da Tabela 7 percebeu-se que as variáveis estratégia ou método de ensino (dimensão docente) e motivação (dimensão discente) apresentam relação com o desempenho acadêmico. Estes resultados corroboram com os achados na primeira análise, quando também se observou significância para as variáveis em questão.

Desta forma, o resultado referente à variável estratégia ou método de ensino vai ao encontro dos estudos de Andrade e Corrar (2008), Cruz, Corrar e Slomski (2008) e Miranda et al. (2015) e discorda de Moura, Miranda e Pereira (2015), que não apresentou significância para a variável em 
questão. Já o achado referente à variável motivação corrobora com as pesquisas de Campbell (2007), Moura, Miranda e Pereira (2015), Miranda et al. (2015) e Rangel e Miranda (2016).

Neste contexto, o Quadro 9 apresenta um comparativo entre as variáveis que apresentaram relação com o desempenho acadêmico na primeira análise e as que apresentaram relação na segunda análise, ou seja, que apresentaram significância estatística.

Quadro 9-Comparativo entre os modelos de medição de desempenho
\begin{tabular}{|c|c|}
\hline Correlação ponto-bisserial & Correlação de Spearman \\
\hline Estratégia ou Método de Ensino (Dimensão docente) & Estratégia ou Método de Ensino (Dimensão docente) \\
\hline Status Socioeconômico (Dimensão discente) & - \\
\hline Absenteísmo (Dimensão discente) & - \\
\hline Desempenho Escolar Anterior (Dimensão discente) & - \\
\hline Horas de Estudo (Dimensão discente) & Motivação (Dimensão discente) \\
\hline Motivação (Dimensão discente) & - \\
\hline Ambiente de Estudo (Dimensão IES) & - \\
\hline Forma de Ingresso (Dimensão IES) & \\
\hline
\end{tabular}

Fonte: Dados da Pesquisa (2017).

Dentre as variáveis apresentadas, somente a estratégia ou método de ensino (dimensão docente e motivação (dimensão discente) apresentaram relação com o desempenho acadêmico em ambas as análises. Isto demonstra que a estratégia ou método de ensino utilizados pelo professor e alunos motivados podem ser benéficos tratando-se de desempenho acadêmico.

Por fim, o fato de todas as hipóteses desta pesquisa não terem sido aceitas alerta que embora algumas variáveis possuam relação com o desempenho acadêmico, quando a análise é direcionada com ênfase nas dimensões, isto não se confirma, uma vez que dentro de cada uma das três dimensões, nem todas as variáveis são significantes. Desta forma, percebe-se que todas as dimensões são importantes para se atingir um melhor desempenho, porém, nem todas as variáveis constantes nestas dimensões são importantes para tal.

\section{CONSIDERAÇÕES FINAIS}

O desempenho acadêmico foi determinado por variáveis classificadas nas três dimensões (corpo docente, corpo discente e IES). Por meio da correlação ponto-bisserial, foi possível identificar relações com o desempenho acadêmico, sendo estas, a estratégia ou método de ensino (dimensão corpo docente), status socioeconômico, absenteísmo, desempenho escolar anterior, horas de estudo e motivação (dimensão corpo discente) e ambiente de estudo e forma de ingresso (dimensão IES).

Partindo para os resultados da percepção dos alunos, segundo a correlação de Spearman, verificou-se que as variáveis estratégia ou método de ensino (dimensão corpo docente) e motivação (dimensão corpo discente) também se mostraram significativas em relação ao desempenho acadêmico, assim como ocorreu na primeira análise. Embora as três hipóteses apresentadas no estudo não tenham sido aceitas, verificaram-se algumas variáveis significantes em cada uma das três dimensões. Ressalta-se que a diferença entre os resultados mencionados neste parágrafo e no anterior, foi a forma de mensuração para as variáveis relacionadas às dimensões docente, discente e IES.

Deste modo, as variáveis identificadas neste estudo como relacionadas ao desempenho acadêmico podem contribuir, de maneira geral, para um melhor processo de ensino-aprendizagem e, por consequência, a possibilidade destes alunos atingirem melhor desempenho em exames tanto internos quanto externos à IES. Além do mais, para que isto possa acontecer, deve haver um vínculo entre aluno, professor e IES, uma vez que pelo menos uma variável se mostrou significativa dentro de cada dimensão (corpo docente, corpo discente e IES).

A contribuição teórica deste estudo se deu pela identificação das variáveis concernentes ao desempenho acadêmico, analisadas de maneira conjunta, dentro das dimensões corpo docente, corpo discente e IES. Em relação às contribuições práticas e sociais, está a formação de profissionais 
contábeis capacitados a desempenhar seu papel na sociedade, além do auxílio às equipes de gestão das IES a visar melhorias nos processos de avaliações do curso, sejam eles internos ou externos.

Além disto, estes gestores podem despender uma especial atenção para aquelas variáveis que apresentaram relação significativa, tanto nos estudos levantados na literatura, quanto nesta pesquisa, uma vez que estas variáveis se tornam relevantes, pois indicam haver, até o momento, um consenso quanto à sua importância para garantir bons níveis de desempenho, sendo elas o absenteísmo, desempenho escolar anterior e motivação (dimensão corpo discente) e forma de ingresso (dimensão IES).

Uma limitação para esta pesquisa se refere à mudança da escala, com a transformação dos dados em variáveis dummy. Embora tenha sido feita com base em outros estudos correlatos, este procedimento pode fazer com que parte da informação se perca ou até mesmo fique limitada. Para futuras pesquisas, sugere-se estudar o tema a partir de uma visão qualitativa, com base no perfil do aluno, seja pela linha da aprendizagem autorregulada ou da andragogia.

Também recomenda-se novos estudos que envolvam as variáveis que apresentam contradições nos resultados obtidos nas diferentes pesquisas, que tornam-se relevantes por seus resultados ainda não serem conclusivos, sendo elas a titulação, qualificação pedagógica e estratégia ou método de ensino (dimensão corpo docente), gênero, idade, etnia, status socioeconômico, escolaridade dos pais, estado civil, número de filhos, atividade remunerada, horas de estudo, horas de sono e nível de ansiedade (dimensão corpo discente) e ambiente de estudo e tamanho da turma (dimensão IES). Por fim, propõe-se investigar as variáveis experiência profissional (dimensão corpo docente), participação em iniciação científica, pesquisa ou extensão (dimensão corpo discente) e frequência de utilização da biblioteca e horário da disciplina (dimensão IES), que embora haja um consenso nos resultados pelas ausências de significância, ainda merecem fazer parte de pesquisas futuras.

\section{REFERÊNCIAS}

Abina, M. B., \& Uthman, A. B. (2018). Internal Brand Equity of Universities and Students' academic Performance: an Empirical Survey of Accounting Students. Global Management Review, 12(1).

Al-Barrak, M. A., \& Al-Razgan, M. S. (2015). Predicting Students' performance Through Classification: A Case Study. Journal of Theoretical \& Applied Information Technology, 75(2).

Alanzi, K. A., \& Alfraih, M. M. (2017). Does accumulated knowledge impact academic performance in cost accounting? Journal of International Education in Business, 10(01), 2-11.

Andrade, J. X., \& Corrar, L. J. (2007). Condicionantes do Desempenho dos Estudantes de Contabilidade: Evidências Empíricas de Natureza Acadêmica, Demográfica e Econômica. Revista de Contabilidade da UFBA, 1(1), 62-74.

Andrietti, V., \& Velasco, C. (2015). Lecture attendance, study time and academic performance: a panel data study. The Journal of Economic Education, 46(3), 239-259.

Araújo, E. A. T., Camargos, M. A., Camargos, M. C. S., \& Dias, A. T. (2013). Desempenho acadêmico de discentes do curso de Ciências Contábeis: uma análise dos seus fatores determinantes em uma IES privada. Contabilidade Vista \& Revista, 24(1), 60-83.

Ballester, C. P. M. (2012). Análisis de los factores que influyen en el desempeño académico de los alumnos de contabilidade financeira através de modelos de eléccion binaria. Revista Brasileira de Gestão de Negócios, 14(5), 379-399.

Barros, R. P., Mendonça, R., Santos, D. D., \& Quintaes, G. (2001). Determinantes do desempenho educacional no Brasil. Pesquisa e Planejamento Econômico, 31(1), 1-42.

Borges, L. F. M., Leal, E. A., Silva, T. D., \& Pereira, J. M. (2018). Rendimento acadêmico e estilos de aprendizagem: um estudo na disciplina análise de custos. Revista Alcance, 25(2), 161-176.

Burrus, R. T., \& Graham, J. E. (2009). Early morning classes and finance student performance. Proceedings of the Financial Education Association. University of North Carolina Wilmington.

Campbell, M. M. (2007). Motivational systems theory and the academic performance of college students. Journal of College Teaching \& Learning (TLC), 4(7), 11-24. 
Conselho Federal de Contabilidade. Resolução CFC no 1.486/2015. Regulamenta o Exame de Suficiência como requisito para obtenção do registro profissional em Conselho Regional de Contabilidade (CRC). Disponível em: <https://cfc.org.br/registro/legislacao/>. Acesso em: 13 dez. 2018.

Corbucci, P. R. (2007). Desafios da educação superior e desenvolvimento no Brasil. Texto para discussão $\mathrm{n}^{\circ}$ 1287. Instituto de Pesquisa Econômica Aplicada (IPEA), Brasília.

Cornachione Junior, E. B., Cunha, J. V. A., Luca, M. M. M., \& Ott, E. (2010). O bom é meu, o ruim é seu: perspectivas da teoria da atribuição sobre o desempenho acadêmico de alunos da graduação em Ciências Contábeis. Revista Contabilidade \& Finanças - USP, 21(53), 1-24.

Cruz, C. V. O. A., Corrar, L. J., \& Slomski, V. (2008). A docência e o desempenho dos alunos dos cursos de graduação em contabilidade no Brasil. Contabilidade Vista \& Revista, 19(4), 15-37.

Das, B. (2014). Higher education on the cross-road. Social Science International, 30(2), 417-426.

Diaz, M. D. M. (2007). Efetividade no ensino superior brasileiro: aplicação de modelos multinível à análise dos resultados do Exame Nacional de Cursos. Revista Economia, 8(1), 93-120.

Eikner, A. E., \& Montondon, L. (2001). Evidence on factors associated with success in intermediate accounting I. The Accounting Educators' Journal, 13(1), 1-17.

Ferreira, M. A. (2015). Determinantes do desempenho discente no ENADE em cursos de Ciências Contábeis (Dissertação de Mestrado). Universidade Federal de Uberlândia, Programa de PósGraduação em Ciências Contábeis, Uberlândia.

Ferreira, A., \& Crisóstomo, J. (2012). A influência do desempenho acadêmico na carreira profissional: um estudo de caso em um curso de engenharia. Revista de Ensino de Engenharia, 30(1), 35-44.

Galvão, N. (2016). Percepção dos contadores sobre o Exame de Suficiência do CFC. Revista Catarinense da Ciência Contábil, 15(45), 49-62.

Glewwe, P. W., Hanushek, E., Humpage, S., \& Ravina, R. (2011). School resources and educational outcomes in developing countries: a review of the literature from 1990 to 2010. National Bureau of Economic Research, 1(w17554).

Guney, Y. (2009). Exogenous and endogenous factors influencing students' performance in undergraduate accounting modules. Accounting Education: an international journal, 18(1), 51-73.

Haile, Y. G., Alemu, S. M., \& Habtewold, T. D. (2017). Insomnia and its temporal association with academic performance among university students: A cross-sectional study. BioMed research international, 2017.

Hair, J., Babin, B., Money, A., \& Samouel, P. (2005). Fundamentos de métodos de pesquisa em administração. Bookman Companhia Ed.

Harrington, D. R., Kulasekera, K., Bates, R., \& Bredahl, M. E. (2006). Determinants of student performance in an undergraduate financial accounting class (No. 1620-2016-134720).

Instituto Nacional de Estudos e Pesquisas Educacionais Anísio Teixeira - INEP. (2017). Exame Nacional de Desempenho dos Estudantes. Disponível em: <http://portal.inep.gov.br/enade>.

Instituto Nacional de Estudos e Pesquisas Educacionais Anísio Teixeira - INEP. (2017). Exame Nacional de Cursos. Disponível em: 〈http://portal.inep.gov.br/enade/enc-provao>.

Karakoc, E. Y. (2016). The Role of Ethical Sensitivity and Self-Esteem on Academic Performance in Accounting Course. Eurasian Journal of Business and Management, 4(2), 95-105.

Keef, S. P., \& Roush, M. L. (1997). New Zealand evidence on the performance of accounting students: race, gender and self-concept. Issues in Accounting Education, 12(2), 315.

Lemos, K. C. S., \& Miranda, G. J. (2015). Alto e Baixo Desempenho no ENADE: que variáveis explicam? Revista Ambiente Contábil, 7(2), 101-118.

Lepp, A., Barkley, J. E., \& Karpinski, A. C. (2014). The relationship between cell phone use, academic performance, anxiety, and satisfaction with life in college students. Computers in Human Behavior, 31(1), 343-350.

Lin, Y., Clough, P. J., Welch, J., \& Papageorgiou, K. A. (2017). Individual differences in mental toughness associate with academic performance and income. Personality and Individual Differences, 113, 178183.

Liu, Y., Robinson, M. N., \& Xu, H. (2018). The Effect of Mindset on Students' Desire to Work for Big Four Accounting Firms and on Academic Performance. e-Journal of Business Education and Scholarship of Teaching, 12(2), 92-106.

Madeira, G. J., Mendonça, K. F. C., \& Abreu, S. M. (2003). A disciplina teoria da contabilidade nos exames de suficiência e provão. Contabilidade Vista \& Revista, 14, 103-122. 
Mamede, S. D. P. N., Marques, A. V. C., Rogers, P., \& Miranda, G. J. (2015). Psychological determinants of academic achievement in accounting: evidence from Brazil. Brazilian Business Review, 12(Special Ed), 50-71.

Mancebo, D., DO VALE, A. A., \& MARTINS, T. B. (2015). Políticas de expansão da educação superior no Brasil 1995-2010. Revista Brasileira de Educação, 20(60), 31-50.

Maniates, M. (2017). Higher education for a post-growth world. The Chronicle Review, 1(7), 10-12.

Masasi, N. J. (2012). How personal attribute affect students' performance in undergraduate accounting course: A case of adult learner in Tanzania. International Journal of Academic Research in Accounting, Finance and Management Sciences, 2(2), 201-211.

Mehmood, F., Sadaf, T., \& Kousar, R. (2017). Gendered academic performance in two public universities in Faisalabad, Pakistan. Science International, 29(4), 711-717.

Meurer, A. M., Pedersini, D. R., Antonelli, R. A., Lopes, I. F., \& Musial, N. T. K. (2018). Relação do Desempenho Academico com Caracteristicas Observaveis e Experiencias Estudantis de Discentes de Ciencias Contabeis. Meta: Avaliação, 10(29), 361-386.

Miranda, G. J. (2011). Relações entre as qualificações do professor e o desempenho discente nos cursos de graduação em contabilidade no Brasil (Tese de Doutorado). Universidade de São Paulo, Programa de Pós-Graduação em Controladoria e Contabilidade, São Paulo.

Miranda, G. J., da Silva Lemos, K. C., de Oliveira, A. S., \& Ferreira, M. A. (2015). Determinantes do desempenho acadêmico na área de negócios. Meta: Avaliação, 7(20), 175-209.

Miranda, G. J., da Castro Casa, S. P., \& Junior, E. B. C. (2013). The accounting education gap in Brazil. China-USA Business Review, 12(4).

Moleta, D., Ribeiro, F., \& Clemente, A. (2017). Fatores Determinantes Para O Desempenho Acadêmico: Uma Pesquisa Com Estudantes De Ciências Contábeis. Revista Capital Científico-Eletrônica, 15(3), 24-41.

Monteiro, S. C., da Silva Almeida, L., \& Vasconcelos, R. M. D. C. F. (2012). Abordagens à aprendizagem, autorregulação e motivação: convergência no desempenho acadêmico excelente. Revista Brasileira de Orientação Profissional, 13(2), 153-162.

Rocha Moura, A. C., Miranda, G. J., \& Pereira, J. M. (2015). Desempenho acadêmico em ciências contábeis: turno noturno versus diurno. Enfoque: Reflexão Contábil, 34(1), 57-70.

Munhoz, A. M. H. (2004). Uma análise multidimensional da relação entre inteligência e desempenho acadêmico em universitários ingressantes (Tese de Doutorado). Universidade Estadual de Campinas, Programa de Pós-Graduação em Educação, Campinas.

Nascimento, C. D. L. (2005). Qualidade do ensino superior de ciências contábeis: um diagnóstico nas instituições localizadas na região norte do estado do Paraná. Revista Base (Administração e Contabilidade) da UNISINOS, 2(3), 155-166.

Nogueira, D. R., Costa, J. D., Takamatsu, R. T., \& Reis, L. D. (2013). Fatores que impactam o desempenho acadêmico: uma análise com discentes do curso de ciências contábeis no ensino presencial. RICRevista de Informação Contábil, 7(3), 51-62.

Paiva, M. O. A., \& Lourenço, A. A. (2011). Rendimento Académico: influência do autoconceito e do ambiente de sala de aula. Psicologia: Teoria e Pesquisa, 27(4), 393-402.

Rangel, J. R., \& Miranda, G. J. (2016). Desempenho Acadêmico e o Uso de Redes Sociais. Sociedade, Contabilidade e Gestão, 11(2).

Rodrigues, B. C., Resende, M. S., Miranda, G. J., \& Pereira, J. M. (2016). Determinantes do desempenho acadêmico dos alunos dos cursos de ciências contábeis no ensino a distância. Enfoque: Reflexão Contábil, 35(2), 139-153.

Ru-Jer, W. (2012). Social class barriers of the massification of higher education in Taiwan. Chinese Education \& Society, 45(5-6), 70-81.

Salas-Velasco, M. (2019). Can educational laws improve efficiency in education production? Assessing students' academic performance at Spanish public universities, 2008-2014. Higher Education, 77(6), 1103-1123.

Santos, N. A. (2012). Determinantes do desempenho acadêmico dos alunos dos cursos de Ciências Contábeis (Tese de Doutorado). Universidade de São Paulo, Programa de Pós-Graduação em Controladoria e Contabilidade, São Paulo. 
Schmidt, S., Zlatkin-Troitschanskaia, O., \& Fox, J. P. (2016). Pretest-Posttest-Posttest Multilevel IRT Modeling of Competence Growth of Students in Higher Education in Germany. Journal of Educational Measurement, 53(3), 332-351.

Smirnov, I., \& Thurner, S. (2017). Formation of homophily in academic performance: Students change their friends rather than performance. PloS one, 12(8).

Smolentseva, A. (2017). Universal higher education and positional advantage: Soviet legacies and neoliberal transformations in Russia. Higher education, 73(2), 209-226.

Soares, H. F. G., \& da Barbedo, C. H. S. (2013). Desempenho acadêmico e a teoria do prospecto: estudo empírico sobre o comportamento decisório. RAC-Revista de Administração Contemporânea, 17(1), 64-82.

Souza, E. S. (2008). ENADE 2006: determinantes do desempenho dos cursos de Ciências Contábeis (Dissertação de Mestrado). Universidade de Brasília/Universidade Federal da Paraíba/Universidade Federal do Rio Grande do Norte, Programa Multi-institucional e Inter-Regional de Pós-Graduação em Ciências Contábeis, Brasília.

Souza, P. V. S. D., Cruz, U. L. D., \& Lyrio, E. F. (2017). A Relação do Exame de Suficiência Contábil com o Desempenho Discente e a Qualidade dos Cursos Superiores em Ciências Contábeis do Brasil. Revista Ambiente Contábil, 9(2), 179-199.

York, T. T., Gibson, C., \& Rankin, S. (2015). Defining and Measuring Academic Success. Practical Assessment, Research \& Evaluation, 20.

Wang, T. (2017). The effect of virtual reality on learning motivation and academic performance $(\mathrm{PhD}$ Thesis). Emporia State University, Department of Instructional Design \& Technology, Emporia - US.

Zaidi, U., Hammad, L. F., Awad, S. S., Qasem, H. D., \& Al-Mahdi, N. A. (2017). Problem-based learning vs. traditional teaching methods: self-efficacy and academic performance among students of health and rehabilitation sciences college, PNU. Science International, 29(3), 547-551.

Zhang, W. (2015). Learning variables, in-class laptop multitasking and academic performance: A path analysis. Computers \& Education, 81, 82-88.

Zonatto, V. C. D. S., Dallabona, L. F., Moura, G. D. D., Domingues, M. J. C. D. S., \& Rausch, R. B. (2013). Evidências da Relação entre Qualificação Docente e Desempenho Acadêmico: uma análise à luz da Teoria do Capital Humano. Sociedade, Contabilidade e Gestão, 8(1). 